\title{
Designing a sustainable biofuel supply chain by considering carbon policies: a case study in Iran
}

\author{
Naeme Zarrinpoor ${ }^{*}$ (I) and Aida Khani
}

\begin{abstract}
Background: Carbon emissions and global warming have increased as a result of population growth and greater usage of fossil fuels. Finding a long-term replacement for fossil fuels, such as biofuels, has become a major problem for energy supply management in recent years. Sustainability must be addressed as a key problem in building biofuel supply chains (BSCs), given the pressing need for societies to limit environmental consequences and promote social responsibility of company activities. Various modeling frameworks have been established so far to design a BSC. At the same time, no research exists that examines both the sustainable development paradigm and the influence of various carbon regulatory policies on the strategic and operational decisions made by BSCs.

Methods: This study develops a multi-objective, multi-period, multi-echelon BSC from switch grass regarding the economic, environmental and social aspects of sustainability. Four carbon policies are taken into account when assessing the environmental aspect: the carbon cap, the carbon tax, the carbon trade, and the carbon offset. To solve the multi-objective model, the fuzzy interactive programming method is used, and the fuzzy best-worst method is used to weight the social objective components.

Results: An actual case study in Iran is studied to demonstrate the model's applicability. Under various carbon policies, different network configurations are obtained based on the location of switch grass resources and installed facilities. Biofuel production and transportation activities account for approximately $28 \%$ and $51 \%$ of total carbon emissions, respectively, according to numerical results. Furthermore, these activities account for roughly $62 \%$ of overall expenses. In the suggested case study, implementing the carbon trade policy reduces carbon emissions by more than $30 \%$ while increasing total profit by about $27 \%$. In comparison to other policies, the carbon trade policy has a substantial impact on enhancing social considerations. Overall, the carbon trade policy can greatly improve the economic and environmental components of sustainability without significantly decreasing in the social sustainability.
\end{abstract}

Conclusions: The proposed model can assist policymakers and governments in simultaneously optimizing BSC profitability, carbon emission reduction, and social concern.

\section{Highlights}

Developing amulti-period and multi-objective model for BSC design.

*Correspondence: zarrinpoor@sutech.ac.ir

Department of Industrial Engineering, Shiraz University of Technology,

Modarres Blvd, P.O. BOX 71555-313, Shiraz, Iran original author(s) and the source, provide a link to the Creative Commons licence, and indicate if changes were made. The images or other third party material in this article are included in the article's Creative Commons licence, unless indicated otherwise in a credit line to the material. If material is not included in the article's Creative Commons licence and your intended use is not permitted by statutory regulation or exceeds the permitted use, you will need to obtain permission directly from the copyright holder. To view a copy of this licence, visit http://creativecommons.org/licenses/by/4.0/. The Creative Commons Public Domain Dedication waiver (http://creativeco mmons.org/publicdomain/zero/1.0/) applies to the data made available in this article, unless otherwise stated in a credit line to the data. 
Considering the proposed model's economic, environmental, andsocial components of the sustainabledevelopment paradigm.

Considering the effectsof various carbon regulatory policies onstrategic and operational decisions.

Weighting social indicators usingthe fuzzy best-worth method.

Validate the proposed model using a real-life casestudy in Iran.

Keywords: Renewable energy, Biofuel supply chain design, Economic growth, Social consideration, Carbon policies

\section{Background}

In recent years, increased use of fossil fuels, unquantifiable greenhouse gas emissions, and an acceleration of global warming have resulted from population growth, urbanization, and industrialization [1]. It is estimated that continuing to use fossil fuels will deplete their finite supplies in less than a century [1-3]. The transportation sector accounts for a significant portion of fuel consumption, greenhouse gas emissions, and operating expenses [4-6]. In 2008, the global percentage of fossil fuel usage was expected to be over $88 \%$. Furthermore, the transportation sector was linked to huge scales of fossil fuel usage [7]. In 2012, the transportation sector's fuel consumption and carbon emissions ratios were approximately $25 \%$ [8] and 22\% [9], respectively. These issues highlight the critical need for society to take a range of steps to find a long-term substitute for fossil fuels and decrease the environmental consequences of commercial operations, particularly in the transportation sector.

Biofuel, as a substitute for fossil fuels, is becoming increasingly important in achieving low-carbon and sustainable society [10]. Biofuel is made from renewable resources and has four generations of development. The first generation of biofuels is generated from food items, such as sugar cane, corn grains, and animal fats. The second generation makes use of nonedible products, such as agricultural residual, switch grass and biomass. The third generation primarily produces biofuels from algae, whereas the fourth generation focuses on materials with lower carbon emissions [11-13]. The first generation has been widely utilized in comparison to succeeding generations, since it does not necessitate the adoption of new and complicated technology. However, the production of first-generation biofuels exacerbated social and ecological issues, such as food scarcity and land use change [14, 15]. The second generation alleviates the problem by utilizing non-edible items, such as Jatropha and agricultural waste. Second-generation biofuels' feedstock requires much less water to cultivate and avoids food competition [6]. Today, the second generation of biofuels is used in most populous and affluent nations, since it emits less carbon than the first generation and has little impact on food supplies $[1,8,16]$.
Controlling carbon emissions is vital for a living and sustainable planet [17]. Concerns about global warming and climate change $[18,19]$ have prompted governments and legislators to establish various carbon emission regulations, such as the carbon cap, carbon tax, carbon trade, and carbon offset [20]. Companies' carbon allowances are limited under the carbon cap policy. The carbon tax policy establishes a penalty for each unit of carbon emitted. In the context of the carbon trade, a trading market can be developed, where enterprises can sell/purchase additional/shortage carbon allowances to continue their industrial activities. Companies can only acquire the additional quantity of carbon allowance to keep their production operations under the carbon offset policy. The policies proposed are aimed at reducing carbon emissions in supply chains. Recent studies have found that these policies have a significant influence on carbon emission reduction, environmental improvement, and supply chain economic profitability [21].

To create an efficient and successful BSC, all areas of sustainability must be considered, according to the importance of sustainable development in the last decade [22]. The economic component of BSC sustainability is the most important because designing BSCs needs a large initial investment and ongoing running costs [23]. The Renewable Fuel Standard (RFS) was established by the United States Congress in 2007 to stimulate biofuel development. According to the RFS in the United States, biofuel production will reach 36 billion gallons per year by 2022, with 21 billion gallons of second-generation biofuels required. Furthermore, the first generation can only create 15 billion gallons of biofuel [24]. The Sustainable Development Goals (SDGs) were adopted by 193 countries in 2015 to safeguard economic, environmental, and social perspectives [25]. Economic growth, the number of new work possibilities produced, the number of days lost due to occupational accidents, the number of employees laid off, and employee job satisfaction are some of the social indicators [26, 27]. Environmental and social factors in BSC designs have received little attention in the literature among SDG indicators. According to certain studies, countries that employ nonedible feedstock to produce biofuels can achieve economic 
growth, lower greenhouse gas emissions, and increase job possibilities, particularly in rural areas [28, 29].

Many researchers have looked into the BSC's design. Zamboni et al. [30] developed a strategic design tool for biomass-based bioethanol supply chains that considers both economic and environmental sustainability. Their proposed mixed integer linear programming (MILP) model was tested in Italy, and the findings revealed that biomass can boost market sales while also lowering environmental impacts. Corsano et al. [31] proposed a sugar cane-based sustainable bioethanol supply chain in which the profit from selling bioethanol is maximized. The BSC from biomass was designed by You and Wang [32] to reduce total cost and greenhouse gas emissions during the installation and operation of facilities. The model of You and Wang [32] was then expanded by You et al. [33], who took into account the social component of sustainability in terms of creating job opportunities. Azadeh et al. [34] presented a multi-period model for boosting BSC profitability that takes into account the location of the facility, the production/distribution system, and material flows. Cambero and Sowlati [35] presented a multi-objective BSC that uses forest and wood residuals to produce biofuels. Hombach et al. [8] provided a mathematical model for designing a secondgeneration BSC that takes greenhouse gas emissions into account with the goal of maximizing net present value in Germany. Fattahi and Govindan [36] built a cost-effective multi-echelon BSC using biomass in the face of variable biomass availability. They took into account greenhouse gas emissions and put the model to the test in a real case study to demonstrate its utility. To reduce supply chain costs, Xie and Huang [37] devised a multi-echelon BSC under uncertainty. In South Colombia, they tested the proposed model and discovered that manufacturing ethanol is more profitable than other biofuels. In a second-generation BSC using corn residue, Kesharwani et al. [15] evaluated both centralized and distributed preprocessing centers, with the goal of reducing BSC costs and carbon emissions. Ghosh and Bakshi [38] created a BSC with the goal of decreasing the negative effects of algal blooms on natural water. Their objectives are to reduce supply chain costs and hazardous runoffs during biofuel production. Nugroho and Zhu [39] devised a mathematical model for planning and optimizing a BSC by taking into account economic, environmental, and social elements of sustainability to lower BSC costs, lower carbon dioxide emissions, and boost gross domestic product. They demonstrated that biodiesel production is more appropriate than ethanol production. Haji Esmaeili et al. [40] suggested a first-generation BSC design that maximizes the profit of the bioethanol supply chain by considering the financial element. Bijarchiyan et al. [41] designed a long-term BSC network that took into account both economic and social factors. Through a case study, they demonstrated that the proposed model may boost BSC profit, job creation, and economic development. Rezaei et al. [42] proposed a scenario-based robust optimization to construct a biodiesel supply chain that takes into account both economic and environmental factors.

In the literature, there are some studies that used various carbon policies in supply chain configurations to evaluate environmental elements of sustainability. Ramudhin et al. [43] developed a MILP model for supply chain design and used goal programming to solve it. The impact of carbon policies on a biodiesel supply chain was investigated by Marufuzzaman et al. [44]. Agrali et al. [45] looked at a mathematical model for a fossil-fired power industry. The suggested model is used to select a preferred policy from a list of options, including carbon capture and storage, carbon capture and utilization, and carbon trading. The study reveals that the carbon capture and utilization is the more preferable policy. In the product configuration under carbon policies, Li et al. [21] proposed a stochastic programming approach. The results of the experiment show that carbon policies can lower product configuration costs. Gonela [20] proposed a carbon-policy-based electricity supply chain model. He demonstrated how a carbon trading policy can benefit the electricity sector's economic and environmental aspects. By incorporating the carbon emission tax, Ahmed and Sarkar [46] developed a sustainable model for second-generation biofuels. The findings revealed that transportation activities release a significant quantity of carbon and create a significant number of employment in rural areas. Li et al. [4] looked at alternative carbon policies for a sustainable coal supply chain design and found that applying a carbon trade policy can greatly cut carbon emissions. He et al. [47] considered carbon policies when designing a supply chain network. They came to the conclusion that intermediate carbon cap amounts are more profitable than tighter carbon cap because they can limit carbon emissions.

We can infer that the majority of prior studies in the context of constructing BSC focus on the economic element of sustainability, with only a few works, namely, Zamboni et al. [30] and You et al. [33], addressing all aspects of sustainability at the same time. While some papers look at environmental challenges in terms of carbon emissions, carbon-related strategies are rarely considered. Only Ahmed and Sarkar [46] evaluated carbon policies when designing the BSC out of all of these studies. In addition, social issues have gotten litthe attention. The majority of studies focus on edible feedstock for biofuel production, such as corn grain, which is classified as a first generation biofuel, while the second-generation biofuel has gotten little attention. A multi-echelon, multi-period, and multi-objective mathematical model for the BSC is also rare. Moreover, none of these researches take the fuzzy best-worth method 
(FBWM) into account when determining the significance of social factors.

In conclusion, the following questions are addressed by this study:

- How can an optimal BSC be designed to meet all of the sustainable development goals, simultaneously?

- How can the BSC be designed to take into account various social indicators, such as the number of new job opportunities, the level of regional development, the number of lost days, the number of employees laid off, and employee job satisfaction by following the Global Reporting Initiative (GRI) guidelines [48]?

- How can one assess the impact of possible carbon regulation measures on the BSC's strategic and operational decisions?

- Is it possible in the proposed supply chain to achieve the desired trade-off between costs, emissions, and social aspects?

This study offers a multi-objective network design for a sustainable BSC that produces biofuels from switch grass resources to satisfy the above-mentioned questions. The economic aspect addresses the entire profit maximization. The suggested model assesses the effects of carbon policies on economic growth, social improvement, and carbon emissions reduction to investigate the environmental element of sustainability. These policies include the carbon cap, carbon tax, carbon trade, and carbon offset. Job opportunities, regional development, employees' job satisfaction, employee's laid-off and lost days due to occupational accidents are all considered in the social element of sustainability. A fuzzy interactive programming method is devised to solve the model. The FBWM is used to calculate the appropriate weight for social components. A practical case study is presented to illustrate the efficiency of the proposed model. Therefore, the main contributions of this paper are as follows:

- Proposing a new multi-echelon, multi-period, and multi-objective mathematical model for constructing a BSC with switch grass resources, pre-processing centers, bio-refineries, and markets.

- Considering the economic, environmental, and social components of the sustainable development paradigm in the proposed model.

- Examining how alternative carbon regulation policies affect strategic and operational decisions.

- Weighting social indicators using the FBWM.

- Use an actual case study in Iran to validate the suggested model.
This study is organized as follows: The "Methods" section builds the mathematical model for the multi-objective sustainable BSC under various carbon policies. The section on "Solution approach" describes how to solve the model using the fuzzy interactive programming and the FBWM. An actual case study and numerical results are presented in the "Results and discussion" section. The section under "Sensitivity analysis" assesses the impact of important factors on the proposed model. Finally, in the "Conclusions" section, the results and future research plans are presented.

\section{Methods}

In light of carbon policies, this paper proposes a multiobjective, multi-period, multi-echelon sustainable BSC for producing switch grass biofuel. Switch grass is a well-known biofuel source. It can grow in a variety of soils with varying nutrient levels, and it requires little water and has a low production cost. Switch grass also has other advantages, such as lowering carbon emissions, improving the economic condition of rural areas, and generating a lot of energy from a single unit [49, 50]. The proposed BSC structure is shown in Fig. 1. The supply chain is made up of switch grass resources, preprocessing centers, bio-refineries, and markets, as can be seen. Switch grasses are transported to preprocessing centers from resources. Preprocessed switch grasses are delivered to bio-refineries, where they are turned into biofuels, and then transported to markets to meet customers' demand. Because of the considerable implications of their production and transportation procedures on the BSC's sustainability, pre-processing facilities and bio-refineries receive the most consideration when developing the BSC. The model takes into account two objective functions. The economic objective function seeks to maximize BSC earnings, whereas the social objective function examines the proposed BSC's social responsibility. Various guidelines and standards for social evaluation have been produced to date, including Guidance on Social Responsibility-ISO 26000 [51], Social Accountability 8000 [52], and GRI [48]. To determine the components of the social aim in this study, GRI guideline indicators [48] were used. As a result, several social indicators, such as job opportunities, regional development, employee job satisfaction, the number of employees laid off, and lost days due to occupational accidents are taken into account. There are also four carbon policies to consider: the carbon cap, the carbon tax, the carbon offset, and the carbon trade. The impact of these policies on BSC profitability, carbon emissions reduction, and social sustainability are assessed. It should be noted that the 


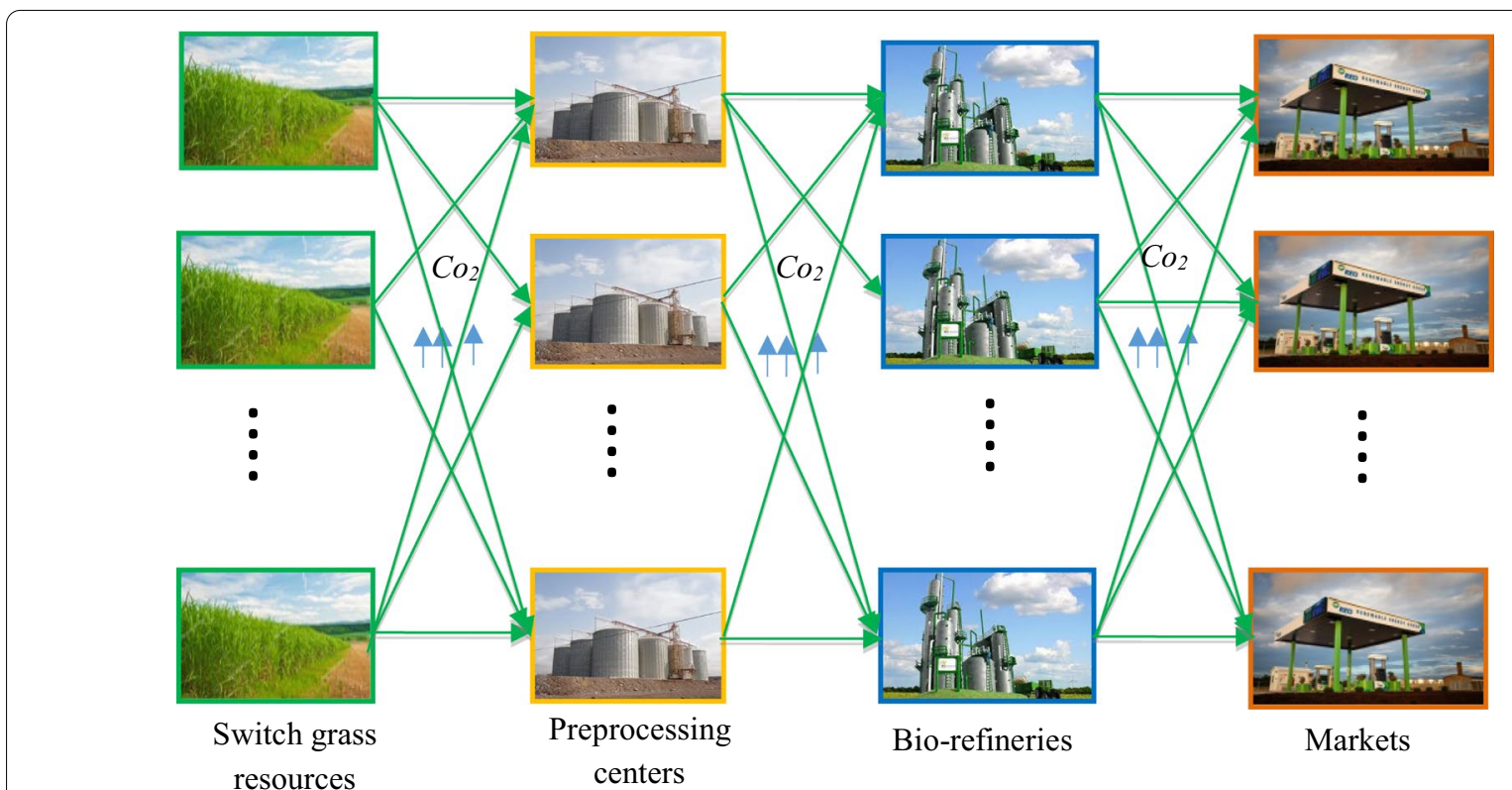

Fig. 1 Illustration of the BSC structure

carbon stored in biomass during the cultivation process is not taken into account in this work.

Road routes connect all of the infrastructures in the projected biofuel network. Furthermore, it is believed that road routes exist between all infrastructures. The transfer of raw materials and finished goods between resource zones and facilities is done by truck. The paper analyzes a multi-period formulation to reflect the dynamic variation of costs, demands, and capacity of switch grass resources, pre-processing facilities, and biorefineries in real-world circumstances. As a result, several strategic and operational decisions are made over a period of time. Locating pre-processing centers and biorefineries, allocating switch grass from resources to preprocessing centers, allocating preprocessed switch grass from preprocessing centers to bio-refineries, and allocating biofuel from bio-refineries to markets are all part of these considerations.

Assumptions This paper is developed based on the following assumptions:

- Biofuel is made from a single feedstock.

- The location of facilities and markets are constant.

- The model under consideration is multi-period and multi-echelon.
- Each period's biofuel demand is predictable and must be met in full.

- The shortage is not permitted.

- The suggested model's economic, environmental, and social elements are all deterministic.

- No safety stock is considered in pre-processing centers or bio-refineries.

- Road transport is used to carry feedstock and biofuel via supply chain levels. Trucks deliver switch grass from resource zones to facilities. Furthermore, biofuel is carried from bio-refineries to markets via tanker.

- The transportation distances between facilities are known.

The capacity of facilities is deterministic and restricted but it can be improved by developing the current equipment and implementing advanced technologies.

In the following, sets, parameters and decision variables are defined.

Sets

1

$J$

K

$M$

$T$
Set of switch grass resources

Set of preprocessing centers

Set of bio-refineries

Set of markets

Set of periods 


\begin{tabular}{|c|c|c|c|}
\hline \multirow{2}{*}{\multicolumn{2}{|c|}{ Parameters }} & & \\
\hline & & $E_{k m}$ & Amount of carbon emissions during \\
\hline$\vartheta$ & Interest rate & \multirow{3}{*}{$C_{k m t}$} & $\begin{array}{l}\text { transporting biofuels from bio- } \\
\text { refinery } k \text { to market } m \text { (Kg per ton) }\end{array}$ \\
\hline$S_{i}$ & Supply capacity of resource $i$ (Ton) & & \\
\hline$R_{k t}$ & $\begin{array}{l}\text { Revenue of bio-refinery } k \text { in period } t \\
\text { (Rial per Gallon) }\end{array}$ & & $\begin{array}{l}\text { bio-refinery } k \text { to market } m \text { in period } \\
t \text { (Rial perTon) }\end{array}$ \\
\hline$F_{j t}$ & $\begin{array}{l}\text { Fixed installation cost of preprocess- } \\
\text { ing center } j \text { in period } t \text { (Rial) }\end{array}$ & $D_{k m}$ & $\begin{array}{l}\text { Distance between bio-refinery } k \text { and } \\
\text { market } m(\mathrm{Km})\end{array}$ \\
\hline$\alpha$ & $\begin{array}{l}\text { Conversion rate at preprocessing } \\
\text { centers }\end{array}$ & $J_{j}$ & $\begin{array}{l}\text { The number of created job opportu- } \\
\text { nities in preprocessing center } j\end{array}$ \\
\hline$P_{j}$ & $\begin{array}{l}\text { Capacity of preprocessing center } j \\
\text { (Ton) }\end{array}$ & \multirow[t]{2}{*}{$J_{j k}$} & \multirow{2}{*}{$\begin{array}{l}\text { The number of created job opportu- } \\
\text { nities in transporting preprocessed } \\
\text { switch grass from preprocessing } \\
\text { center } j \text { to bio-refinery } k\end{array}$} \\
\hline$F_{k t}$ & $\begin{array}{l}\text { Fixed installation cost of bio-refinery } \\
k \text { in period } t \text { (Rial) }\end{array}$ & & \\
\hline$\beta$ & Conversion rate at bio-refineries & \multirow[t]{2}{*}{$J_{k}$} & \multirow{2}{*}{$\begin{array}{l}\text { The number of created job opportu- } \\
\text { nities in bio-refinery } k\end{array}$} \\
\hline$P_{k}$ & Capacity of bio-refinery k (Ton) & & \\
\hline$D_{m t}$ & $\begin{array}{l}\text { Demand of biofuel in market } m \text { in } \\
\text { period } t \text { (Ton) }\end{array}$ & $J_{\mathrm{km}}$ & $\begin{array}{l}\text { The number of created job opportu- } \\
\text { nities in transporting biofuels from } \\
\text { bio-refinery } k \text { to market } m\end{array}$ \\
\hline$C_{i t}^{b}$ & $\begin{array}{l}\text { Harvesting, collecting and loading } \\
\text { costs of switch grass in resource } i \text { in } \\
\text { period } t \text { (Rial per ton) }\end{array}$ & $L_{j}$ & $\begin{array}{l}\text { The number of lost days due to } \\
\text { occupational accidents in preproc- } \\
\text { essing center } j\end{array}$ \\
\hline$C_{i t}^{h}$ & $\begin{array}{l}\text { Storage cost of switch grass in } \\
\text { resource } i \text { in period } t \text { (Rial per ton) }\end{array}$ & \multirow[t]{2}{*}{$L_{k}$} & \multirow{2}{*}{$\begin{array}{l}\text { The number of lost days due to } \\
\text { occupational accidents in bio- } \\
\text { refinery } k\end{array}$} \\
\hline \multirow[t]{2}{*}{$C_{i j t}$} & \multirow{2}{*}{$\begin{array}{l}\text { Transportation cost of switch grass } \\
\text { from resource } i \text { to preprocessing } \\
\text { center } j \text { in period } t \text { (Rial per ton) }\end{array}$} & & \\
\hline & & $F r_{j}$ & $\begin{array}{l}\text { The number of employees' laid-off } \\
\text { in preprocessing center } j\end{array}$ \\
\hline$D_{i j}$ & $\begin{array}{l}\text { Distance between resource } i \text { and } \\
\text { preprocessing center } j(\mathrm{Km})\end{array}$ & $F r_{k}$ & $\begin{array}{l}\text { The number of employees' laid-off } \\
\text { in bio-refinery } k\end{array}$ \\
\hline \multirow[t]{2}{*}{$E_{i}$} & \multirow{2}{*}{$\begin{array}{l}\text { Amount of carbon emissions during } \\
\text { growing, harvesting, collecting and } \\
\text { loading of switch grass in resource i } \\
\text { (Kg per ton) }\end{array}$} & $S_{j t}$ & $\begin{array}{l}\text { Employees' job satisfaction in pre- } \\
\text { processing center } j \text { in period } t\end{array}$ \\
\hline & & $S_{k t}$ & Employees' job satisfaction in bio- \\
\hline \multirow[t]{3}{*}{$E_{i j}$} & \multirow{3}{*}{$\begin{array}{l}\text { Amount of carbon emissions during } \\
\text { transporting switch grass from } \\
\text { resource } i \text { to preprocessing center } j \\
\text { (Kg per ton) }\end{array}$} & & refinery $k$ in period $t$ \\
\hline & & $W a_{j t}$ & $\begin{array}{l}\text { Employees' welfare cost in preproc- } \\
\text { essing center } j \text { in period } t \text { (Rial) }\end{array}$ \\
\hline & & $W a_{k t}$ & Employees' welfare cost in bio- \\
\hline \multirow[t]{2}{*}{$F C_{j t}$} & \multirow{2}{*}{$\begin{array}{l}\text { Fixed preprocessing cost in pre- } \\
\text { processing center } j \text { in period } t \text { (Rial } \\
\text { per ton) }\end{array}$} & & refinery $k$ in period $t$ (Rial) \\
\hline & & $W_{1}$ & $\begin{array}{l}\text { The weight of work opportunity in } \\
\text { the social objective }\end{array}$ \\
\hline$V C_{j t}$ & $\begin{array}{l}\text { Variable preprocessing cost in } \\
\text { preprocessing center } j \text { in period } t \\
\text { (Rial per ton) }\end{array}$ & $W_{2}$ & $\begin{array}{l}\text { The weight of regional develop- } \\
\text { ment in the social objective }\end{array}$ \\
\hline \multirow[t]{2}{*}{$E_{j}$} & Amount of carbon emissions during & $W_{3}$ & $\begin{array}{l}\text { The weight of employees'job satis- } \\
\text { faction in the social objective }\end{array}$ \\
\hline & $\begin{array}{l}\text { preprocessing switch grass in pre- } \\
\text { processing center } j \text { (Kg per ton) }\end{array}$ & $W_{4}$ & $\begin{array}{l}\text { The weight of employees'laid-off in } \\
\text { the social objective }\end{array}$ \\
\hline$E_{j k}$ & $\begin{array}{l}\text { Amount of carbon emissions during } \\
\text { transporting the preprocessed } \\
\text { switch grass from preprocessing }\end{array}$ & $W_{5}$ & $\begin{array}{l}\text { The weight of lost days in the social } \\
\text { objective }\end{array}$ \\
\hline & center $j$ to bio-refinery $k$ (Kg per ton) & $\mathrm{b}_{j}$ & Regional development level of \\
\hline$C_{j k t}$ & Transportation cost of preprocessed & & preprocessing center $j$ \\
\hline & $\begin{array}{l}\text { switch grass from preprocessing } \\
\text { center } j \text { to bio-refinery } k \text { in period } t\end{array}$ & $b_{k}$ & $\begin{array}{l}\text { Regional development level of bio- } \\
\text { refinery } k\end{array}$ \\
\hline & (Rial per ton) & $\mathrm{va}_{j}$ & Economic value of installing pre- \\
\hline$D_{j k}$ & Distance between preprocessing & & processing center $j$ \\
\hline & center $j$ and bio-refinery k (Km) & $v a_{k}$ & Economic value of installing bio- \\
\hline$F C_{k t}$ & Fixed operating cost in bio-refinery & & refinery $k$ \\
\hline & $k$ in period $t$ (Rial) & $C_{1 t}^{c a p}$ & Maximum amount of carbon emis- \\
\hline$V C_{k t}$ & $\begin{array}{l}\text { Variable operating cost in bio- } \\
\text { refinery } k \text { in period } t \text { (Rial per ton) }\end{array}$ & & $\begin{array}{l}\text { sions in switch grass resources in } \\
\text { period } t\end{array}$ \\
\hline$E_{k}$ & $\begin{array}{l}\text { Amount of carbon emissions during } \\
\text { producing biofuel in bio-refinery } k \\
\text { (Kg per ton) }\end{array}$ & $c_{2 t}^{c a p}$ & $\begin{array}{l}\text { Maximum amount of carbon emis- } \\
\text { sions in preprocessing centers in } \\
\text { period } t\end{array}$ \\
\hline
\end{tabular}




\begin{tabular}{cl}
\hline$C_{3 t}^{\text {cap }}$ & Maximum amount of carbon emis- \\
$T_{t}$ & sions in bio-refineries in period $t$ \\
& Tax rate on emitting carbon in \\
& period $t$ \\
$\rho_{t}$ & Carbon selling price in period $t$ (Rial \\
& per kg) \\
& Carbon purchasing price in period $t$ \\
$\theta_{t}$ & (Rial per kg) \\
Variables & \\
Binary variables & \\
$Y_{j t}$ & 1 If preprocessing center $j$ is \\
$Y_{k t}$ & installed in period $t, 0$ otherwise \\
& 1 If bio-refinery $k$ is installed in \\
Continues variables & period $t$, 0 otherwise \\
$X_{i j t}$ & \\
& Amount of transported switch grass \\
& from resource $i$ to preprocessing \\
$X_{j k t}$ & center $j$ in period $t$ (Ton) \\
& Amount of transported preproc- \\
& essed switch grass from preproc- \\
& essing center $j$ to bio-refinery $k$ in \\
& period $t$ (Ton)
\end{tabular}

\begin{tabular}{|c|c|}
\hline$X_{k m t}$ & $\begin{array}{l}\text { Amount of transported biofuel from } \\
\text { bio-refinery } k \text { to market } m \text { in period } \\
t \text { (Ton) }\end{array}$ \\
\hline$e_{1 t}^{+}$ & $\begin{array}{l}\text { Amount of the purchased carbon } \\
\text { in switch grass resources in period } \\
t(\mathrm{Kg})\end{array}$ \\
\hline$e_{1 t}^{-}$ & $\begin{array}{l}\text { Amount of the soled carbon in } \\
\text { switch grass resources in period } t \\
(\mathrm{Kg})\end{array}$ \\
\hline$e_{2 t}^{+}$ & $\begin{array}{l}\text { Amount of the purchased carbon } \\
\text { in preprocessing centers in period } \\
t(\mathrm{Kg})\end{array}$ \\
\hline$e_{2 t}^{-}$ & $\begin{array}{l}\text { Amount of the soled carbon in pre- } \\
\text { processing centers in period } t(\mathrm{Kg})\end{array}$ \\
\hline$e_{3 t}^{+}$ & $\begin{array}{l}\text { Amount of the purchased carbon in } \\
\text { bio-refineries in period } t(\mathrm{Kg})\end{array}$ \\
\hline$e_{3 t}^{-}$ & $\begin{array}{l}\text { Amount of the soled carbon in bio- } \\
\text { refineries in period } t(\mathrm{Kg})\end{array}$ \\
\hline
\end{tabular}

Model formulation

In the following, the mathematical formulation of the basic model is presented:

$$
\begin{aligned}
& \operatorname{Max} z_{1}=\sum_{t} \frac{1}{(1+\vartheta)^{t-1}}\left[\sum_{k} \sum_{m} R_{k t} X_{k m t}-\sum_{j} F_{j t}\left(Y_{j t}-Y_{j t-1}\right)-\sum_{k} F_{k t}\left(Y_{k t}-Y_{k t-1}\right)\right. \\
& -\sum_{i} \sum_{j} X_{i j t}\left(C_{i t}^{b}+C_{i t}^{h}\right)-\sum_{i} \sum_{j} D_{i j} C_{i j t} X_{i j t}-\sum_{i} \sum_{j}\left(F C_{j t}+V C_{j t}\right) X_{i j t} \\
& -\sum_{j} \sum_{k} D_{j k} C_{j k t} X_{j k t}-\sum_{j} \sum_{k}\left(F C_{k t}+V C_{k t}\right) X_{j k t}-\sum_{k} \sum_{m} D_{k m} C_{k m t} X_{k m t} \\
& \left.-\sum_{j} W a_{j t}\left(Y_{j t}-Y_{j t-1}\right)-\sum_{k} W a_{k t}\left(Y_{k t}-Y_{k t-1}\right)\right] \\
& \operatorname{Max}_{2}=W_{1}\left(\sum_{j} \sum_{k} \sum_{t}\left(J_{j}+J_{j k}\right)\left(Y_{j t}-Y_{j t-1}\right)+\sum_{k} \sum_{m} \sum_{t}\left(J_{k}+J_{k m}\right)\left(Y_{k t}-Y_{k t-1}\right)\right) \\
& +W_{2}\left(\sum_{j} \sum_{t} v a_{j}\left(1-b_{j}\right)\left(Y_{j t}-Y_{j t-1}\right)+\sum_{k} \sum_{t} v a_{k}\left(1-b_{k}\right)\left(Y_{k t}-Y_{k t-1}\right)\right) \\
& +W_{3}\left(\sum_{j} \sum_{t} S_{j t}\left(Y_{j t}-Y_{j t-1}\right)+\sum_{k} \sum_{t} S_{k t}\left(Y_{k t}-Y_{k t-1}\right)\right) \\
& -W_{4}\left(\sum_{j} \sum_{t} F r_{j}\left(Y_{j t}-Y_{j t-1}\right)+\sum_{k} \sum_{t} F r_{k}\left(Y_{k t}-Y_{k t-1}\right)\right) \\
& -W_{5}\left(\sum_{j} \sum_{t} L_{j}\left(Y_{j t}-Y_{j t-1}\right)+\sum_{k} \sum_{t} L_{k}\left(Y_{k t}-Y_{k t-1}\right)\right)
\end{aligned}
$$


s.t.

$\sum_{j} X_{i j t} \leq S_{i} \forall i, t$

$\sum_{k} X_{j k t} \leq P_{j} \forall j, t$

$\sum_{m} X_{k m t} \leq P_{k} \forall k, t$

$\sum_{i} \alpha X_{i j t}=\sum_{k} X_{j k t} \forall j, t$

$\sum_{j} \beta X_{j k t}=\sum_{m} X_{k m t} \forall k, t$

$\sum_{k} X_{k m t}=D_{m t} \forall m, t$

$\sum_{i} X_{i j t} \leq M Y_{j t} \forall j, t$

$\sum_{j} X_{j k t} \leq M Y_{k t} \forall k, t$

$Y_{j t} \geq Y_{j t-1} \forall j, t$

$Y_{k t} \geq Y_{k t-1} \forall k, t$

$X_{i j t}, X_{j k t}, X_{k m t} \geq 0 \forall i, j, m, k, t$

$Y_{j t} \in\{0,1\} \forall j, t$

$Y_{k t} \in\{0,1\} \forall k, t$

The objective function (1) seeks to maximize the profit from the sale of biofuels. The total revenue is considered in the first term. The costs of installation, harvesting, collecting, loading and storing switch grass, as well as transportation and production, are all included in the first objective. Objective function (2) promotes job opportunity, regional development, and employee job satisfaction while reducing the amount of employees laid off and days lost due to occupational accidents. Constraint (3) ensures that the amount of switch grass delivered from each resource to preprocessing centers does not exceed the resources' supply capacity.
Constraints (4) and (5) ensure that the amount of preprocessed switch grass transported to bio-refineries and the amount of biofuel delivered to markets does not exceed the capacity of the preprocessing centers and biorefineries, respectively. Constraint (6) is used to maintain a balance between the amount of switch grass delivered from resources to preprocessing centers and the amount of preprocessed switch grass transferred to bio-refineries. The balance between the amount of preprocessed switch grass from preprocessing centers to bio-refineries and the amount of biofuels to markets is specified by constraint (7). Constraint (8) is considered to satisfy market demands. The switch grass and preprocessed switch grass are transferred to preprocessing centers and bio-refineries, respectively, according to constraints (9) and (10). Constraints (11) and (12) state that each preprocessing center and bio-refinery must be built in a certain period and stay operational in subsequent period. The types of decision variables are determined by constraints (13) to (15).

The extension of the model by considering carbon policies In the following section, the suggested model is extended under four carbon policies to assess the effects of environmental concerns on the BSC.

\section{The extended model under the carbon cap policy}

The amount of carbon consumption for a corporation is limited to the stated value under the carbon cap policy. As a result, constraints (16) to (18) are added to the proposed model for expressing this policy on the BSC, yielding the following model:

$\operatorname{Max} z_{1}, \operatorname{Max} z_{2}$ s.t. (3-15)

$$
\begin{aligned}
& \sum_{i} \sum_{j}\left(E_{i}+E_{i j}\right) X_{i j t} \leq C_{1 t}^{c a p} \forall t \\
& \sum_{j} \sum_{k}\left(E_{j}+E_{j k}\right) X_{j k t} \leq C_{2 t}^{c a p} \forall t \\
& \sum_{k} \sum_{m}\left(E_{k}+E_{k m}\right) X_{k m t} \leq C_{3 t}^{c a p} \forall t
\end{aligned}
$$

The carbon emissions from switch grass resource activities are limited, according to constraint (16). These activities include growing, harvesting, collecting, loading, storage and transportation of switch grass. Constraints (17) and (18) set the maximum quantity of carbon emissions allowed in the BSC for preprocessing and generating operations, respectively.

\section{The extended model under the carbon tax policy}

A distinct tax is considered for each unit of emitted carbon in the context of carbon tax policy. This policy, 
unlike the carbon cap policy, has no restriction on the amount of carbon released. Under this policy, the following model will be proposed:

$$
\sum_{j} \sum_{k}\left(E_{j}+E_{j k}\right) X_{j k t}+e_{2 t}^{-} \leq C_{2 t}^{c a p}+e_{2 t}^{+} \forall t
$$

$\operatorname{Max} z_{2}$

$$
\begin{aligned}
\operatorname{Max} z_{1}=\sum_{t} \frac{1}{(1+\vartheta)^{t-1}} & {\left[\sum_{k} \sum_{m} R_{k t} X_{k m t}-\sum_{j} F_{j t}\left(Y_{j t}-Y_{j t-1}\right)-\sum_{k} F_{k t}\left(Y_{k t}-Y_{k t-1}\right)\right.} \\
& -\sum_{i} \sum_{j} X_{i j t}\left(C_{i t}^{b}+C_{i t}^{h}\right)-\sum_{i} \sum_{j} D_{i j} C_{i j t} X_{i j t}-\sum_{i} \sum_{j}\left(F C_{j t}+V C_{j t}\right) X_{i j t} \\
& -\sum_{j} \sum_{k} D_{j k} C_{j k t} X_{j k t}-\sum_{j} \sum_{k}\left(F C_{k t}+V C_{k t}\right) X_{j k t}-\sum_{k} \sum_{m} D_{k m} C_{k m t} X_{k m t} \\
& -\sum_{j} W a_{j t}\left(Y_{j t}-Y_{j t-1}\right)-\sum_{k} W a_{k t}\left(Y_{k t}-Y_{k t-1}\right)-\sum_{i} \sum_{j} T x_{t}\left(E_{i}+E_{i j}\right) X_{i j t} \\
& \left.-\sum_{j} \sum_{k} T x_{t}\left(E_{j}+E_{j k}\right) X_{j k t}-\sum_{k} \sum_{m} T x_{t}\left(E_{k}+E_{k m}\right) X_{k m t}\right]
\end{aligned}
$$

\section{s.t. $(3-15)$.}

\section{The extended model under the carbon trade policy}

A trading market for carbon use is formed under the carbon trade policy. If a company requires more carbon allowance to continue operating, it can buy the amount of carbon allowance it lacks from enterprises with more carbon allowance than the maximum level. The following is the proposed model for the carbon trade policy:

$\operatorname{Max} z_{2}$

$$
\begin{aligned}
& \sum_{k} \sum_{m}\left(E_{k}+E_{k m}\right) X_{k m t}+e_{3 t}^{-} \leq C_{3 t}^{c a p}+e_{3 t}^{+} \forall t \\
& e_{1 t}^{+}, e_{1 t}^{-}, e_{2 t}^{+}, e_{2 t}^{-}, e_{3 t}^{+}, e_{3 t}^{-} \geq 0 \forall t
\end{aligned}
$$

According to constraints (21) to (23), switch grass resources, preprocessing centers and bio-refineries can purchase the amount of the carbon shortage or sell the amount of additional carbon allowance to keep their activities, respectively. The type of decision variables is defined by constraint (24).

$$
\begin{aligned}
\operatorname{Max} z_{1}=\sum_{t} \frac{1}{(1+\vartheta)^{t-1}} & {\left[\sum_{k} \sum_{m} R_{k t} X_{k m t}-\sum_{j} F_{j t}\left(Y_{j t}-Y_{j t-1}\right)-\sum_{k} F_{k t}\left(Y_{k t}-Y_{k t-1}\right)\right.} \\
& -\sum_{i} \sum_{j} X_{i j t}\left(C_{i t}^{b}+C_{i t}^{h}\right)-\sum_{i} \sum_{j} D_{i j} C_{i j t} X_{i j t}-\sum_{i} \sum_{j}\left(F C_{j t}+V C_{j t}\right) X_{i j t} \\
& -\sum_{j} \sum_{k} D_{j k} C_{j k t} X_{j k t}-\sum_{j} \sum_{k}\left(F C_{k t}+V C_{k t}\right) X_{j k t}-\sum_{k} \sum_{m} D_{k m} C_{k m t} X_{k m t} \\
& -\sum_{j} W a_{j t}\left(Y_{j t}-Y_{j t-1}\right)-\sum_{k} W a_{k t}\left(Y_{k t}-Y_{k t-1}\right)-\rho_{t}\left(e_{1 t}^{+}-e_{1 t}^{-}\right) \\
& \left.-\rho_{t}\left(e_{2 t}^{+}-e_{2 t}^{-}\right)-\rho_{t}\left(e_{3 t}^{+}-e_{3 t}^{-}\right)\right]
\end{aligned}
$$

$$
\begin{aligned}
& \text { s.t.(3-15) } \\
& \qquad \sum_{i} \sum_{j}\left(E_{i}+E_{i j}\right) X_{i j t}+e_{1 t}^{-} \leq C_{1 t}^{c a p}+e_{1 t}^{+} \forall t
\end{aligned}
$$

The extended model under the carbon offset policy

The carbon offset and carbon trade policies use the same method; however, under this policy, a corporation cannot sell more carbon allowances to other companies. The following is a model formulation for this policy: 
$\operatorname{Maxz}_{2}$

Step 1 . For each objective, specify positive and negative ideal solutions as follows:

$$
\begin{aligned}
\operatorname{Max} z_{1}=\sum_{t} \frac{1}{(1+\vartheta)^{t-1}} & {\left[\sum_{k} \sum_{m} R_{k t} X_{k m t}-\sum_{j} F_{j t}\left(Y_{j t}-Y_{j t-1}\right)-\sum_{k} F_{k t}\left(Y_{k t}-Y_{k t-1}\right)\right.} \\
& -\sum_{i} \sum_{j} X_{i j t}\left(C_{i t}^{b}+C_{i t}^{h}\right)-\sum_{i} \sum_{j} D_{i j} C_{i j t} X_{i j t}-\sum_{i} \sum_{j}\left(F C_{j t}+V C_{j t}\right) X_{i j t} \\
& -\sum_{j} \sum_{k} D_{j k} C_{j k t} X_{j k t}-\sum_{j} \sum_{k}\left(F C_{k t}+V C_{k t}\right) X_{j k t}-\sum_{k} \sum_{m} D_{k m} C_{k m t} X_{k m t} \\
& \left.-\sum_{j} W a_{j t}\left(Y_{j t}-Y_{j t-1}\right)-\sum_{k} W a_{k t}\left(Y_{k t}-Y_{k t-1}\right)-\theta_{t} e_{1 t}^{+}-\theta_{t} e_{2 t}^{+}-\theta_{t} e_{3 t}^{+}\right]
\end{aligned}
$$

$$
\begin{aligned}
& \text { s.t. (3-15) } \\
& \sum_{i} \sum_{j}\left(E_{i}+E_{i j}\right) X_{i j t} \leq C_{1 t}^{c a p}+e_{1 t}^{+} \forall t \\
& \sum_{j} \sum_{k}\left(E_{j}+E_{j k}\right) X_{j k t} \leq C_{2 t}^{c a p}+e_{2 t}^{+} \forall t \\
& \sum_{k} \sum_{m}\left(E_{k}+E_{k m}\right) X_{k m t} \leq C_{3 t}^{c a p}+e_{3 t}^{+} \forall t \\
& e_{1 t}^{+}, e_{2 t}^{+}, e_{3 t}^{+} \geq 0 \forall t
\end{aligned}
$$

Switch grass resources, preprocessing centers, and biorefineries can purchase the shortage amount of the carbon allowance to continue their production operations, according to constraints (26) to (28). Constraint (29) shows the type of decision variables.

\section{Solution approach}

A two-stage solution approach is devised to solve the proposed model. In the first stage, a fuzzy interactive programming approach is suggested for solving the multi-objective model. In the second stage, the FBWM is used to determine the weight of social components.

\section{The fuzzy interactive programming approach}

In recent research, fuzzy approaches have been primarily used to solve multi-objective models. Because of their ability to determine the satisfaction level of objective functions, fuzzy approaches are referred to as strong approaches [53]. Decision-makers can select the most effective option based on this solution. The provided multi-objective model is solved in this study using an attractive fuzzy programming approach established by Torabi and Hassini [53]. Below is a description of this procedure.

$$
\begin{aligned}
& Z_{1}^{\mathrm{PIS}}=\max Z_{1}, Z_{1}^{\mathrm{NIS}}=\min Z_{1} \\
& Z_{2}^{\mathrm{PIS}}=\max Z_{2}, Z_{2}^{\mathrm{NIS}}=\min Z_{2}
\end{aligned}
$$

Step 2. For each objective, create a linear membership function as follows:

$$
\mu_{k}(v)=\left\{\begin{array}{ccr}
1 & \text { if } Z_{k}>Z_{k}^{\mathrm{PIS}} & k=1,2 \\
\frac{Z_{k}-Z_{k}^{\mathrm{NIS}}}{Z_{k}^{\mathrm{PIS}}-Z_{k}^{\mathrm{NIS}}} & \text { if } Z_{k}^{\mathrm{NIS}} \leq Z_{k} \leq Z_{k}^{\mathrm{PIS}} & k=1,2 \\
0 & \text { if } Z_{k}<Z_{k}^{\mathrm{NIS}} & k=1,2
\end{array}\right.
$$

Step 3. Convert the multi-objective model to a singleobjective model using the following formula:

$$
\begin{aligned}
& \text { s.t. } \\
& \lambda_{0} \leq \mu_{k}(v) k=1,2 \\
& v \in F(v), \\
& \gamma, \lambda_{0} \in[0,1]
\end{aligned}
$$$$
\max \lambda(v)=\gamma \lambda_{0}+(1-\gamma) \sum_{k} \theta_{k} \mu_{k}(v)
$$

$F(v)$ represents the feasible region. The compensation coefficient and the importance of objective $k$ are denoted by $\gamma$ and $\theta_{k}$, respectively. Decision makers define $\theta_{k}$ values based on their importance, and $\sum_{k} \theta_{k}=1, \theta_{k}>0 . \mu_{k}(v)$ signifies the level of satisfaction with objective $k$, and

Table 1 Linguistic variables and the equivalent fuzzy number [55]

\begin{tabular}{lr}
\hline Linguistic variables & Membership function \\
\hline Equally importance (El) & $(1,1,1)$ \\
Weakly important $(\mathrm{Wl})$ & $(2 / 3,1,3 / 2)$ \\
Fairly important $(\mathrm{Fl})$ & $(3 / 2,2,5 / 2)$ \\
Very important $(\mathrm{VI})$ & $(5 / 2,3,7 / 2)$ \\
Absolutely important (Al) & $(7 / 2,4,9 / 2)$ \\
\hline
\end{tabular}


$\lambda_{0}=\min _{k}\left\{\mu_{k}(v)\right\}$ is the lowest level of satisfaction with objectives.

\section{The fuzzy best-worst method}

Rezaei [54] proposes the best-worst method for determining the weight of criteria based on pairwise comparison. In this procedure, a decision maker selects the best and worst criteria, then assesses the best criterion's preference over others and other criteria's preference over the worst criterion [54]. Guo and Zhao [55] devised the FBWM in response to the uncertainty of real-world problems and the ambiguity of decision-makers' opinions. This method is used for weighting social objective components because of the FBWM's capability to deal with the ambiguity of real-world circumstances. The following are the steps involved in this method:

Step 1. Determine a set of related criteria.

Step 2 . Specify the best $\left(C_{B}\right)$ and the worst $\left(C_{W}\right)$ criteria by a decision maker.

Step 3. Using the linguistic variables in Table 1, specify the fuzzy preference of the best criterion over others. $\tilde{A}_{B}=\left(\tilde{a}_{B 1}, \tilde{a}_{B 2}, \ldots, \tilde{a}_{B n}\right)$ is the fuzzy best evaluation vector. Note that $\tilde{a}_{B j}$ denotes the best criteria's fuzzy preference for criterion $j$, and $\tilde{a}_{B B}=(1,1,1)$.

Step 4. Using the linguistic variables in Table 1, assign the fuzzy preference of other criteria to the worst criterion. $\tilde{A}_{W}=\left(\tilde{a}_{1 W}, \tilde{a}_{2 W}, \ldots, \tilde{a}_{n W}\right)$ is the fuzzy vector of the others to the worst criterion. $\tilde{a}_{j W}$ is the fuzzy preference of criteria $j$ over the worst criterion, and $\tilde{a}_{W W}=(1,1,1)$.

Step 5. Compute the optimal fuzzy weights $\left(\tilde{W}_{1}^{*}, \tilde{W}_{2}^{*}, \ldots, \tilde{W}_{n}^{*}\right)$.

If the absolute difference between $\left|\frac{\tilde{w}_{B}}{\tilde{w}_{j}}-\tilde{a}_{B j}\right|$ and $\left|\frac{\tilde{w}_{j}}{\tilde{w}_{W}}-\tilde{a}_{j W}\right|$ for all $j$ can be minimized, fuzzy weights can be derived. It's worth noting that $\tilde{w}_{B}, \tilde{w}_{j}$, and $\tilde{w}_{W}$ are all triangular fuzzy numbers. The resultant $\tilde{w}_{j}=\left(l_{j}^{w}, m_{j}^{w}, u_{j}^{w}\right)$ must be converted to its crisp equivalent. The following is the FBWM formulation:

$$
\begin{aligned}
& \min _{j} \max _{j}\left\{\left|\frac{\tilde{w}_{B}}{\tilde{w}_{j}}-\tilde{a}_{B j}\right|,\left|\frac{\tilde{w}_{j}}{\tilde{w}_{W}}-\tilde{a}_{j W}\right|\right\} \\
& \text { s.t. } \\
& \sum_{j=1}^{n} R \widetilde{\left(w_{j}\right)}=1 \\
& l_{j}^{w} \leq m_{j}^{w} \leq u_{j}^{w} \\
& l_{j}^{w} \geq 0 \\
& j=1,2, \ldots, n
\end{aligned}
$$

In Eq. (33), $\tilde{w}_{B}=\left(l_{B}^{w}, m_{B}^{w}, u_{B}^{w}\right), \tilde{w}_{j}=\left(l_{j}^{w}, m_{j}^{w}, u_{j}^{w}\right)$, $\tilde{w}_{W}=\left(l_{W}^{W}, m_{W}^{W}, u_{W}^{w}\right)$ $\tilde{a}_{j W}=\left(l_{j W}, m_{j W}, u_{j W}\right)$.
The above model can be stated as follows:

$\min \tilde{\xi}$

s.t.

$\left|\frac{\tilde{w}_{B}}{\tilde{w}_{j}}-\tilde{a}_{B j}\right| \leq \tilde{\xi}$

$\left|\frac{\tilde{w}_{j}}{\tilde{w}_{W}}-\tilde{a}_{j W}\right| \leq \tilde{\xi}$

$\sum_{j=1}^{n} R \widetilde{\left(w_{j}\right)}=1$

$l_{j}^{w} \leq m_{j}^{w} \leq u_{j}^{w}$

$l_{j}^{w} \geq 0$

$j=1,2, \ldots, n$

where $\tilde{\xi}=\left(l^{\xi}, m^{\xi}, u^{\xi}\right)$. By considering $l^{\xi} \leq m^{\xi} \leq u^{\xi}$ and $\xi=\left(k^{*}, k^{*}, k^{*}\right), k^{*} \leq l^{\xi}$, model (34) is reformulated as follows:W

$$
\min \tilde{\xi}^{*}
$$

s.t.

$$
\begin{aligned}
& \left|\frac{\left(l_{B}^{w}, m_{B}^{w}, u_{B}^{w}\right)}{\left(l_{j}^{w}, m_{j}^{w}, u_{j}^{w}\right)}-\left(l_{B j}, m_{B j}, u_{B j}\right)\right| \leq\left(k^{*}, k^{*}, k^{*}\right) \\
& \left|\frac{\left(l_{j}^{w}, m_{j}^{w}, u_{j}^{w}\right)}{\left(l_{W}^{w}, m_{W}^{w}, u_{W}^{w}\right)}-\left(l_{j W}, m_{j W}, u_{j W}\right)\right| \leq\left(k^{*}, k^{*}, k^{*}\right) \\
& \left.\sum_{j=1}^{n} R \widetilde{\left(w_{j}\right.}\right)=1 \\
& l_{j}^{w} \leq m_{j}^{w} \leq u_{j}^{w} \\
& l_{j}^{w} \geq 0 \\
& j=1,2, \ldots, n
\end{aligned}
$$

Solving the presented model (35) will yield the optimal fuzzy weights. After that, Eq. (36) is used to transform them to crisp values:

$$
\widetilde{R\left(w_{j}\right)}=\frac{l_{j}^{w}+4 m_{j}^{w}+u_{j}^{w}}{6}
$$

\section{Results and discussion}

In this section, the proposed models are applied to a realworld case study in Iran. The most compelling reasons for developing biofuels in Iran are population growth, environmental concerns, and rising fossil fuel consumption [56]. Iran can produce a variety of biofuel feedstocks, including corn, sunflower, and switch grass [57]. It also contains promising agricultural zones, as well as 


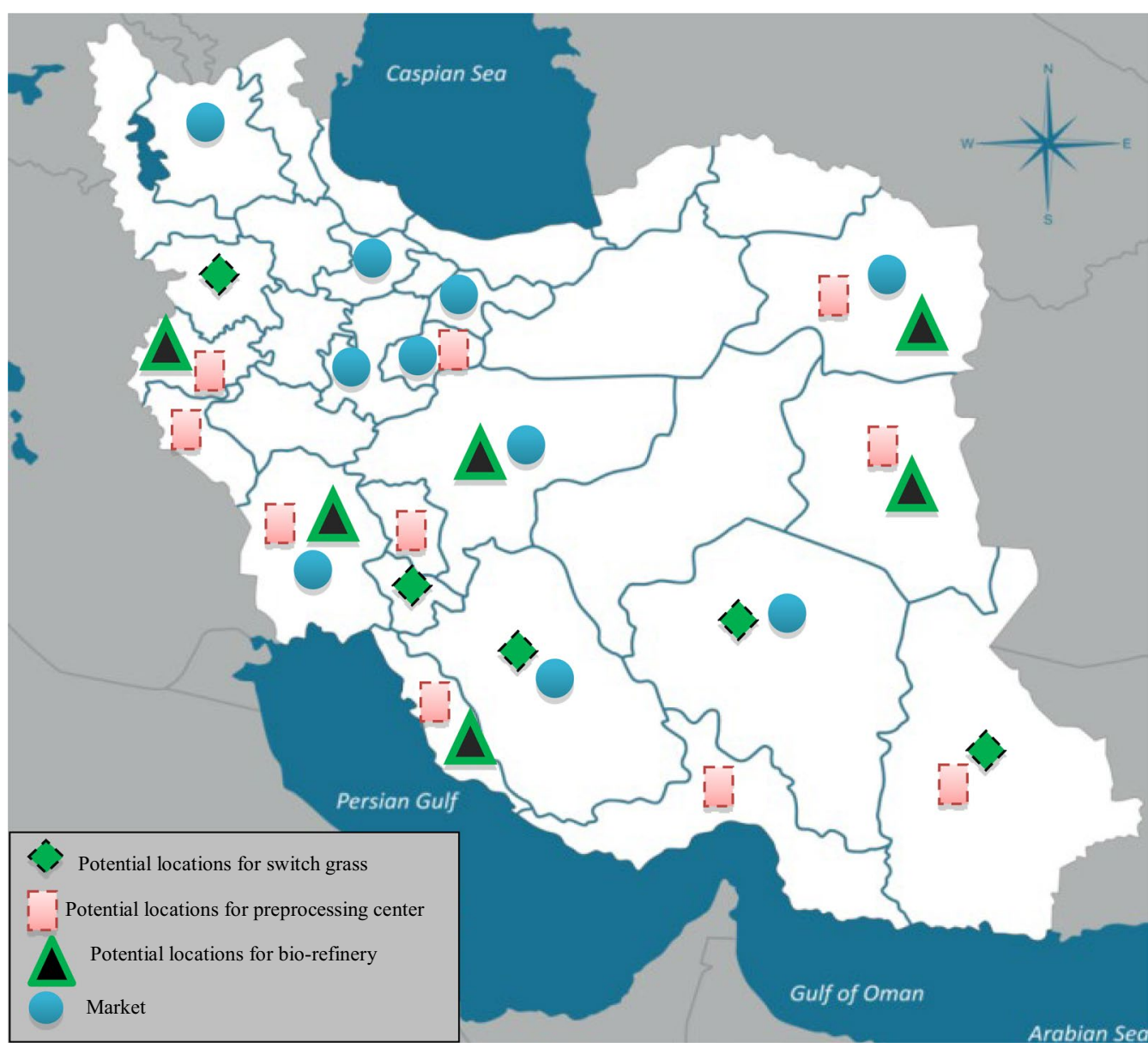

Fig. 2 Geographic map of Iran and potential locations for facilities

favorable meteorological and geographical conditions for switch grass cultivation [50]. Switch grass is an inedible feedstock, as previously indicated. In comparison to edible feedstocks, it is recognized as a suitable and profitable feedstock for biofuel production [40]. Planning is done over a 4-year planning horizon. A map of Iran is shown in Fig. 2.

As can be seen, switch grass resources are assessed in five prospective provinces. These provinces were chosen based on yearly rainfall, accessible water resources, geographic circumstances, available space for switch grass cultivation, soil potential for producing switch grass, and available equipment and methods for cultivation, according to Ghaderi et al. [58]. It should be highlighted that the above-mentioned elements also influence the capacity of switch grass resources. Preprocessing centers and biorefineries will be built in ten and six provinces, respectively. These regions were chosen based on geographical and climatic circumstances, distances from human societies, communication channels, and faults, among other factors. Furthermore, Iran's most populous provinces with significant energy use are chosen as biofuel markets. It should be emphasized that these populated provinces have greater transportation and industrial operations than other provinces.

The case study's numerical results are presented. GAMS 24.1.2 is used to code the proposed models. All tests are run on a laptop with an Intel Core i5 $5200 \mathrm{U}$ CPU (2.20 GHz), 4.00 GB of RAM, and a 64-bit operating system. The range of case study parameters is shown in Table 2. It's worth noting that facility installation costs are calculated based on their location, utilized technologies and capacity. The expenses of pre-processing and biofuel production are evaluated based on the materials, labor force, machinery, energy supply sources, climatic conditions of the located facilities, etc. These expenses are estimated using the Iran Customer Price Index. Previous feasibility studies in Iran are also taken into account. During a 4-year planned horizon, the cost of biofuel will climb by $10 \%$ every year. Transportation 
Table 2 Range of parameters

\begin{tabular}{llllll}
\hline Parameter & Range & Parameter & Range & Parameter & Range \\
\hline$\vartheta$ & 0.15 & $C_{j k t}$ & {$[0,15200]$} & $S_{j t}$ & {$[50 \%, 87 \%]$} \\
$S_{i}$ & $D_{j k}$ & {$[0,1581]$} & $S_{k t}$ & {$[57 \%, 87 \%]$} \\
$R_{k t}$ & {$[500,000,700,000]$} & $F C_{k t}$ & {$\left[5 \times 10^{7}, 5.4 \times 10^{7}\right]$} & $W_{j t}$ & {$[180000,206000]$} \\
$F_{j t}$ & {$\left[76 \times 10^{7}, 79 \times 10^{7}\right]$} & $V C_{k t}$ & {$\left[2 \times 10^{\prime}, 5 \times 10^{\prime}\right]$} & $W_{k t}$ & {$[190000,208000]$} \\
$\alpha$ & {$\left[50 \times 10^{9}, 72 \times 10^{9}\right]$} & $E_{k}$ & {$[2055.6,2065.6]$} & $b_{j}$ & {$[60 \%, 90 \%]$} \\
$P_{j}$ & 0.45 & $E_{k m}$ & {$[0.2022,0.2033]$} & $b_{k}$ & {$[60 \%, 85 \%]$} \\
$F_{k t}$ & {$[300,000,400,000]$} & $C_{k m t}$ & {$[0,15200]$} & $v_{j}$ & {$[13,19]$} \\
$\beta$ & {$\left[400 \times 10^{9}, 680 \times 10^{9}\right]$} & $D_{k m}$ & {$[0,1754]$} & $v_{k}$ & {$[14,19]$} \\
$P_{k}$ & 0.80 & $J_{j}$ & {$[150,220]$} & $C_{1 t}$ & {$\left[52 \times 10^{6}, 63 \times 10^{6}\right]$} \\
$D_{m t}$ & {$[300,000,340,000]$} & $J_{j k}$ & {$[5,13]$} & $C_{2 t}^{c a p}$ & {$\left[80 \times 10^{6}, 88 \times 10^{6}\right]$} \\
$C_{i t}^{b}$ & {$[35000,70000]$} & $J_{k}$ & {$[180,290]$} & $C_{3 t}^{c a p}$ & {$\left[12 \times 10^{8}, 13 \times 10^{8}\right]$} \\
$C_{i t}^{h}$ & {$[8000000,12000000]$} & $J_{k m}$ & {$[6,15]$} & $T_{x}$ & {$[30 \%, 35 \%]$} \\
$C_{i j t}$ & {$[500000,600000]$} & $L_{j}$ & {$[22,27]$} & $\rho_{t}$ & {$[30000,31000]$} \\
$D_{i j}$ & {$[0,17200]$} & $L_{k}$ & {$[17,22]$} & $\theta_{t}$ & {$[50000,50050]$} \\
$E_{i}$ & {$[0,1784]$} & $V C_{j t}$ & {$[10000000,40000000]$} & $E_{j}$ & {$[14.3,17.2]$} \\
$E_{i j}$ & {$[3,4.5]$} & $E_{j k}$ & {$[0.2022,0.2024]$} & $F_{r k}$ & {$[14,21]$} \\
$F C_{j t}$ & {$[0.2002,0.2005]$} & $F r_{j}$ & {$[12,17]$} & &
\end{tabular}

Table 3 Fuzzy preference of the best social component over other components

\begin{tabular}{|c|c|c|c|c|c|}
\hline Social components & Work opportunities & Regional development & Employees' job satisfaction & Employees' laid-off & Lost days \\
\hline $\begin{array}{l}\text { Best component (Regional devel- } \\
\text { opment) }\end{array}$ & $(1.5,2,2.5)$ & $(1,1,1)$ & $(3.5,4,4.5)$ & $(2.5,3,3.5)$ & $(2.5,3,3.5)$ \\
\hline
\end{tabular}

Table 4 Fuzzy preference of other social components over the worst component

\begin{tabular}{ll}
\hline Social components & $\begin{array}{l}\text { Worst component } \\
\text { (Employees' job } \\
\text { satisfaction) }\end{array}$ \\
\hline Work opportunities & $(1.5,2,2.5)$ \\
Regional development & $(3.5,4,4.5)$ \\
Employees'job satisfaction & $(1,1,1)$ \\
Employees'laid-off & $(0.66,1,1.5)$ \\
Lost days & $(1.5,2,2.5)$ \\
\hline
\end{tabular}

costs are determined by the kind of loading items, distances between facilities, and vehicle capacity. Because each facility is in a separate city in Iran, road lengths between cities are calculated using data from the Ministry of Roads and Urban Development [59].

We used published studies on creating sustainable supply chains such as Ghelichi et al. [60], Meyer et al. [61], Rahimi et al. [62], and Perez et al. [10] to measure the social indicators. According to Ghelichi et al. [60],
Table 5 Weight of social objective components

\begin{tabular}{llllll}
\hline Weight & $W_{1}$ & $W_{2}$ & $W_{3}$ & $W_{4}$ & $W_{5}$ \\
\hline Value & 0.2394 & 0.3765 & 0.1531 & 0.1243 & 0.1067 \\
\hline
\end{tabular}

the number of newly created fixed job opportunities in preprocessing centers is estimated to be between 150 and 220, while that in bio-refineries is estimated to be between 180 and 290. Furthermore, we calculated that transportation activities create between 5 and 15 fixed job opportunities. According to Meyer et al. [61], the regional development coefficient in pre-processing centers is between 0.6 and 0.9 , while it is between 0.6 and 0.85 in bio-refineries. According to Rahimi et al. [62], the number of days lost due to occupational accidents in preprocessing centers is estimated to be between 22 and 27 days, whereas that in bio-refineries is estimated to be between 17 and 22 days. The number of employees laid off in preprocessing centers is estimated to be between 12 and 17 operatives, while the number of employees laid 


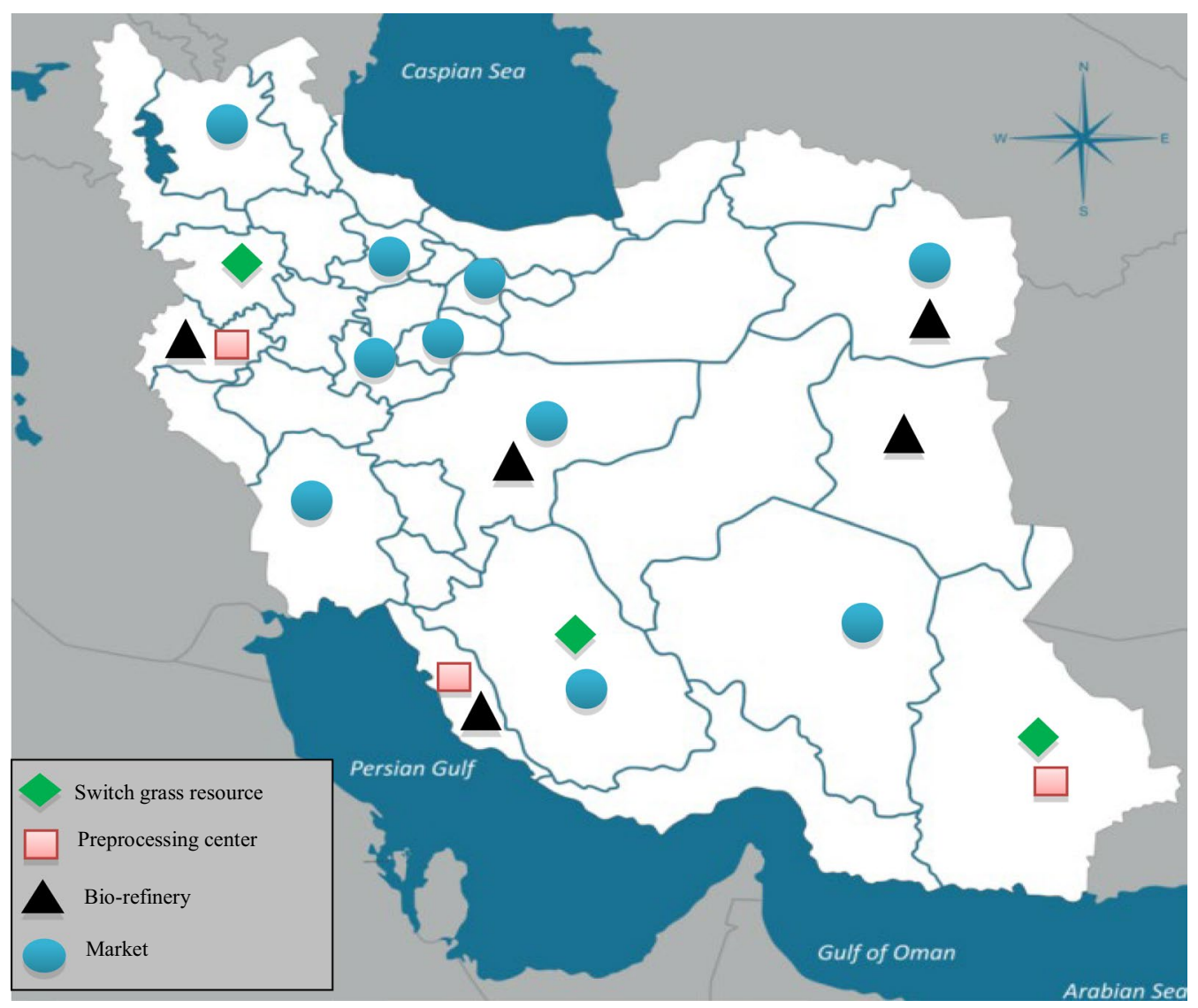

Fig. 3 The optimal design of the basic model

Table 6 Numerical results of the basic model

\begin{tabular}{lllll}
\hline$\mu_{1}$ & $\mu_{2}$ & $z_{1}$ (Rial) & $z_{2}$ & $\begin{array}{l}\text { Carbon emissions } \\
\text { (Kg) }\end{array}$ \\
\hline 0.771 & 0.142 & $1,240,490,000,000,000$ & 5634.695 & $1,817,763,000$ \\
\hline
\end{tabular}

off in bio-refineries is estimated to be between 14 and 21 operatives. According to Perez et al. [10], employee job satisfaction in preprocessing centers is estimated to be between 50 and $87 \%$, while it is estimated to be between 57 and $87 \%$ in bio-refineries.

Tables 3, 4 show the decision maker's fuzzy preferences for the best social component over other components, as well as various social components over the worst component. The ideal weight of social objective components generated by the FBWM is shown in Table 5 .

From solving the basic model, Fig. 3 graphically depicts the best sites for preprocessing centers and biorefineries. Kurdistan, Fars, and Sistan and Baluchestan are the three provinces chosen as switch grass resources, as can be observed. Kermanshah, Bushehr, and Sistan and Baluchestan each have one preprocessing center. Kermanshah, Bushehr, Esfahan, Razavi Khorasan, and South Khorasan each have one bio-refinery. The numerical results of solving the basic model are shown in Table 6.

Figure 4 depicts the amount of carbon emissions in several BSC sectors of the basic model. According to this data, bio-refineries account for a significant portion of the total supply chain's carbon emissions. Furthermore, transportation between different levels of the BSC accounts for $51 \%$ of carbon emissions. Switch grass resources account for the smallest percentage of the entire environmental impacts of the BSC, accounting for only $8 \%$ of total carbon emissions. Different carbon policies are being considered in attempt to reduce carbon emissions.

The components of the economic objective are depicted in Fig. 5. The expenses of operating activities such as growing, harvesting, collecting, preprocessing and producing biofuel account for $12 \%, 26 \%$ and $24 \%$ of total BSC costs, respectively, according to this data. As a result, these components account for the majority of the 

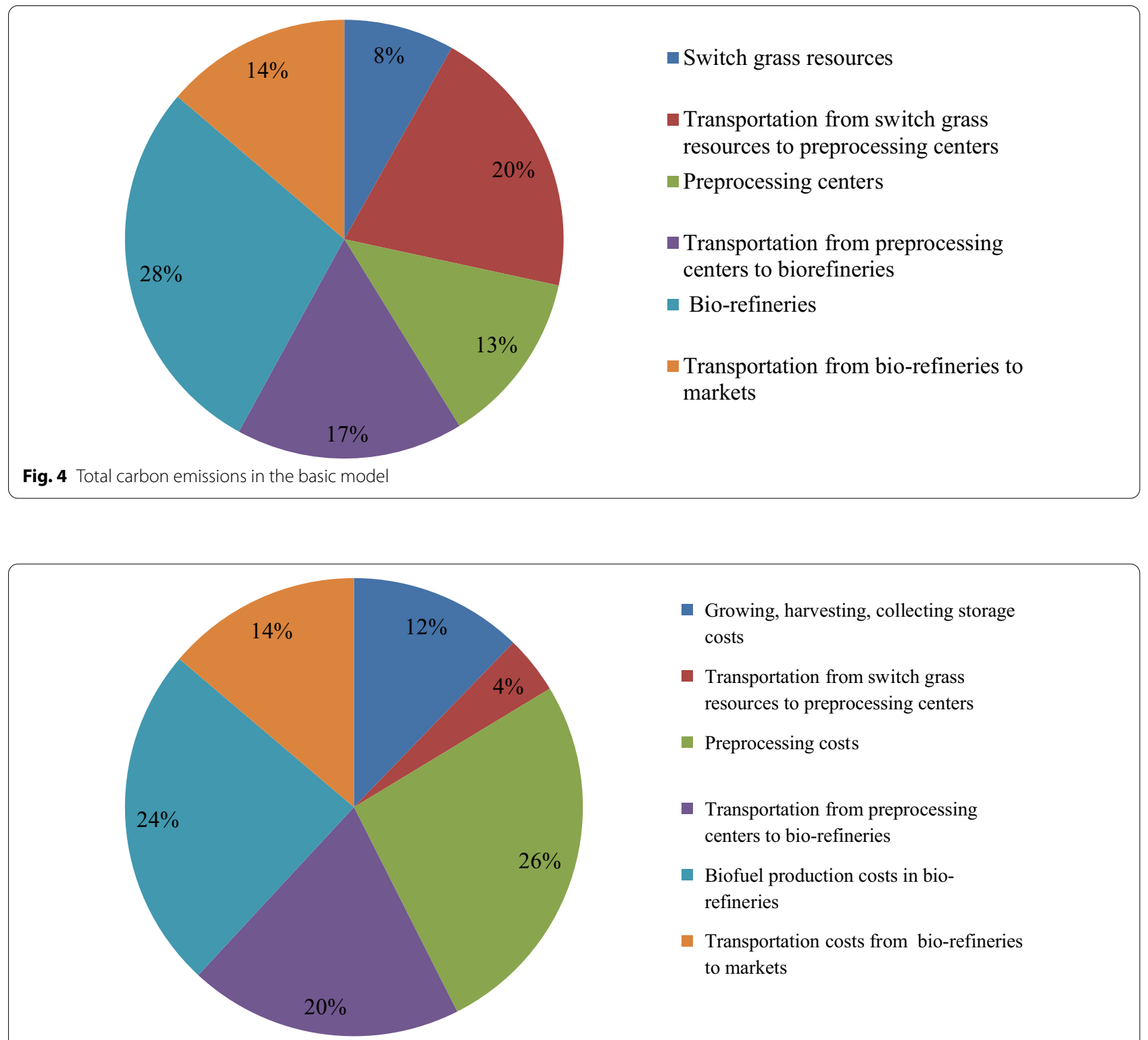

Growing, harvesting, collecting storage costs

- Transportation from switch grass resources to preprocessing centers

- Preprocessing costs

Transportation from preprocessing centers to bio-refineries

- Biofuel production costs in biorefineries

- Transportation costs from bio-refineries to markets

Fig. 5 Components of the economic objective of the basic model

entire cost. Moreover, the transportation sector accounts for $38 \%$ of the entire BSC cost. It's worth noting that greater biofuel production costs lead to higher market price. Increasing the capacity of facilities using innovative technology is one feasible method for lowering the total cost of the BSC.

The components of the social objective are demonstrated in Fig. 6. As illustrated in Fig. 6, the installation of preprocessing centers and bio-refineries in the basic model creates a substantial number of job opportunities, with this social indicator accounting for $85 \%$ of the overall social objective. Employees' job satisfaction, regional development and employees' laid-off play a minor influence, accounting for only $1 \%, 2 \%$, and $3 \%$ of the social objective, respectively. It should be highlighted that one of the most pressing social concerns in any society is job opportunities, particularly in rural areas, and this model has the potential to considerably address this necessity.

The effects of various carbon policies on the basic model are evaluated based on the relevance of lowering carbon emissions in the BSC. Figure 7 depicts the best BSC design for various carbon policies.

Note that policies 1 through 4 depict the carbon cap, carbon tax, carbon trade, and carbon offset policies, respectively. Different alternatives for the location of 


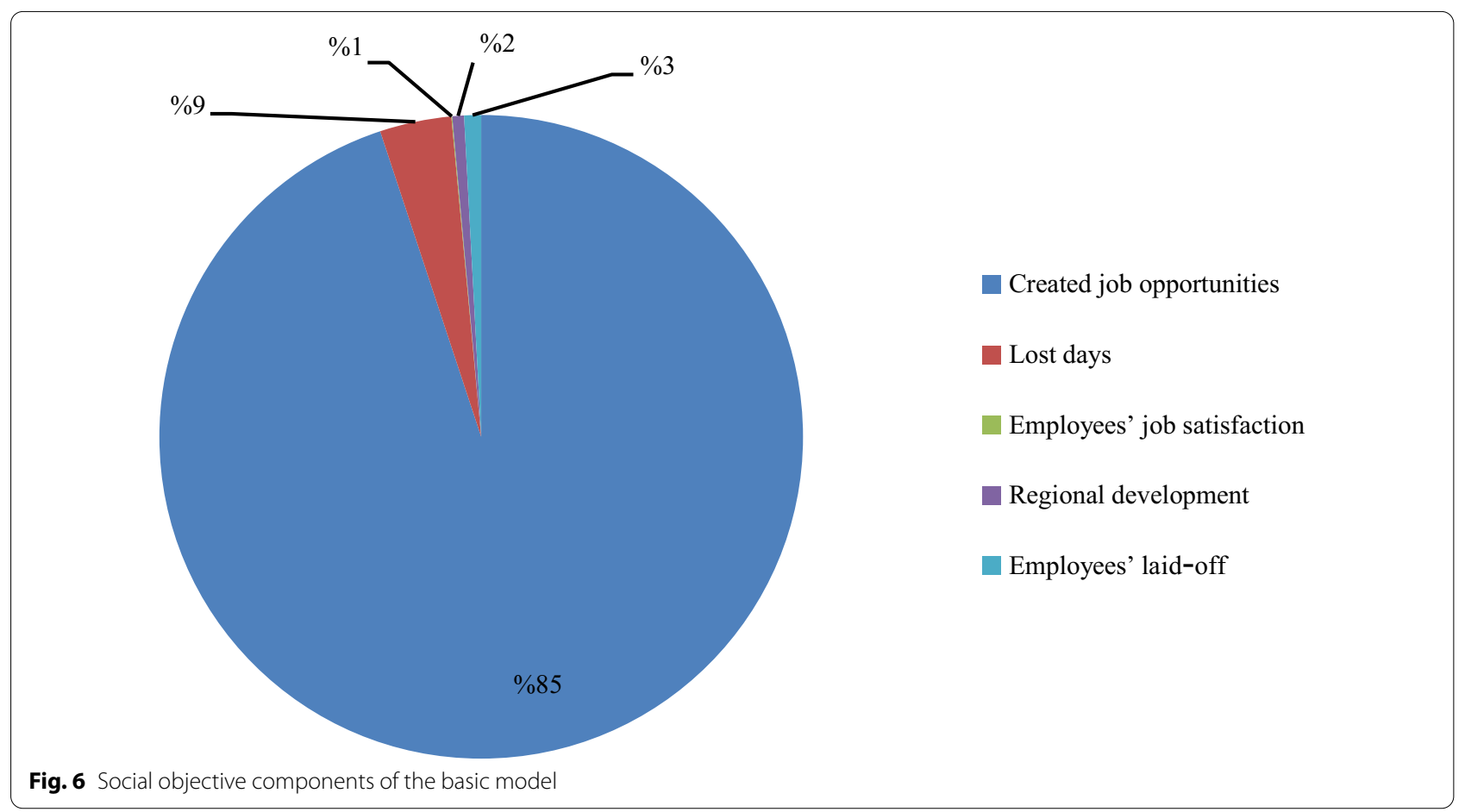

switch grass resources, preprocessing facilities, and biorefineries are evident. Kermanshah, Esfahan, Bushehr, Khuzestan, Razavi Khorasan, and South Khorasan, for example, have been chosen for the installation of biorefineries under the carbon tax policy. Kermanshah, Esfahan, Bushehr, and South Khorasan are the 4 provinces chosen for bio-refineries under the carbon offset policy.

Table 7 summarizes the optimal results of the proposed models. According to this table, the carbon trade policy yields solutions with the highest degree of satisfaction for the economic objective value, whereas the carbon offset policy yields solutions with the highest degree of satisfaction for the social objective value. Note that $\mathrm{Z}$ shows the objective function of the fuzzy interactive programming method proposed in model (32).

The profit of the BSC under various carbon policies, as well as the basic model, are shown in Fig. 8. According to this figure, the BSC gains the highest economic profit through the carbon trade. Carbon tax, carbon trade, and carbon offset policies boost the economic value by $16 \%, 27 \%$ and $5 \%$, respectively. Furthermore, imposing a carbon cap policy reduces profitability by about $11 \%$ because it restricts the amount of carbon allowance available for various operational operations.

Figure 9 shows the consequences of the social objective under various carbon policies and the basic model. Carbon cap, carbon tax, carbon trade and carbon offset policies all reduce the social value by around $5 \%$,
$7 \%, 2 \%$ and $4 \%$, respectively. As a result, in this case study, it can be argued that implementing carbon policies is ineffective in enhancing the social component. However, in comparison to other policies, the carbon trade policy is the most important, while the carbon tax policy is the poorest in terms of enhancing social considerations.

The total quantity of carbon emissions in the BSC under various carbon policies and the basic model is depicted in Fig. 10. Carbon cap, carbon tax, carbon trade, and carbon offset policies result in reductions in carbon emissions of over $24 \%, 2 \%, 30 \%$, and $8 \%$, respectively. Therefore, the BSC is revealed to have the lowest carbon emissions under the carbon trade policy. Most BSC facilities can sell their excess carbon allowance on the existing trading market, resulting in a significant reduction in their carbon emissions.

Based on prior findings, it can be inferred that enacting carbon policies has a major impact on supply chain profitability, social considerations, and the reduction of carbon emissions. Furthermore, due to a $27 \%$ rise in the economic value of the BSC compared to the basic model, the carbon trade policy can be regarded the most profitable policy. In addition, the carbon trade policy is the most environmentally friendly policy because it can reduce carbon emissions by more than $30 \%$ when compared to the basic model. These policies have a substantial impact on strategic facility location decisions. As a result, applying these policies may be the most effective 


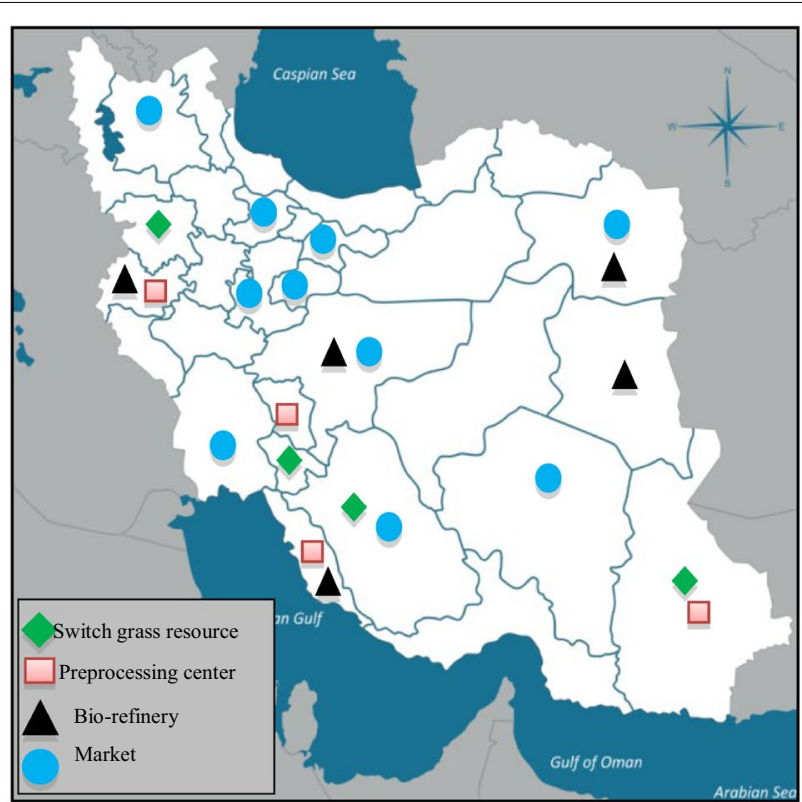

a) Policy 1 .

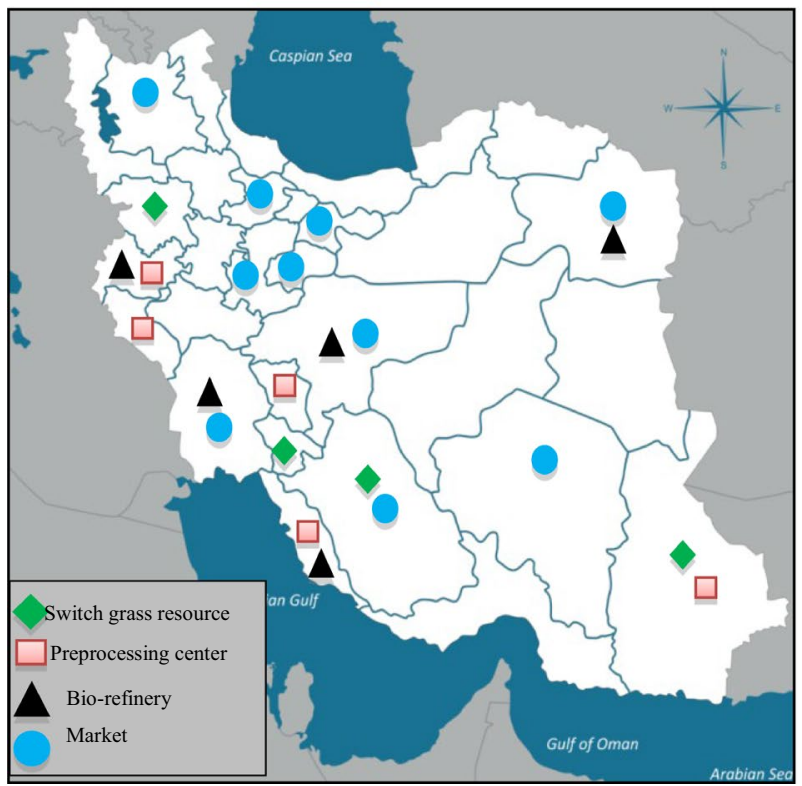

c) Policy 3 .

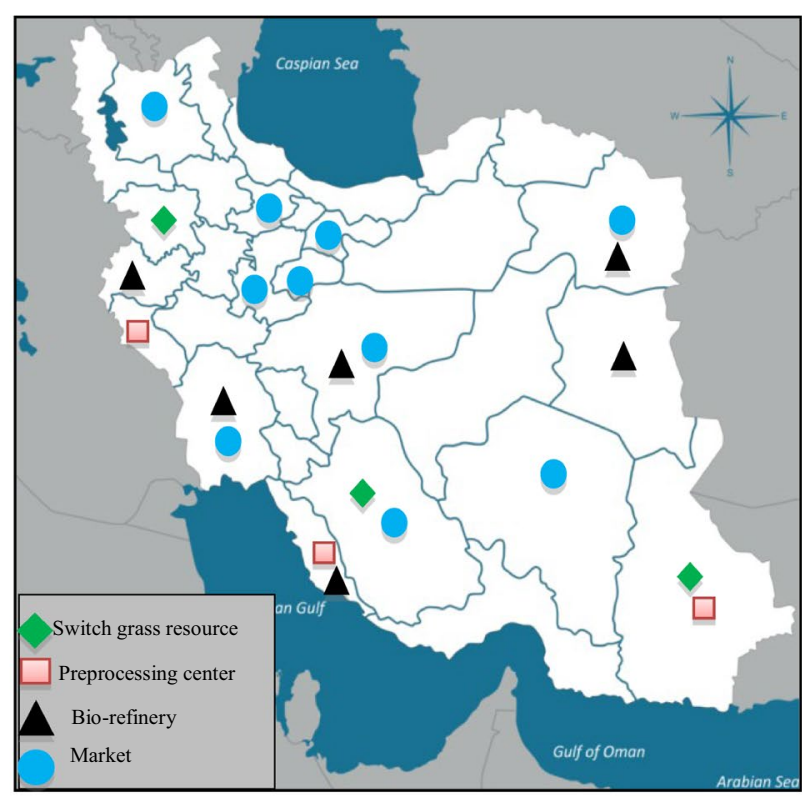

b) Policy 2 .

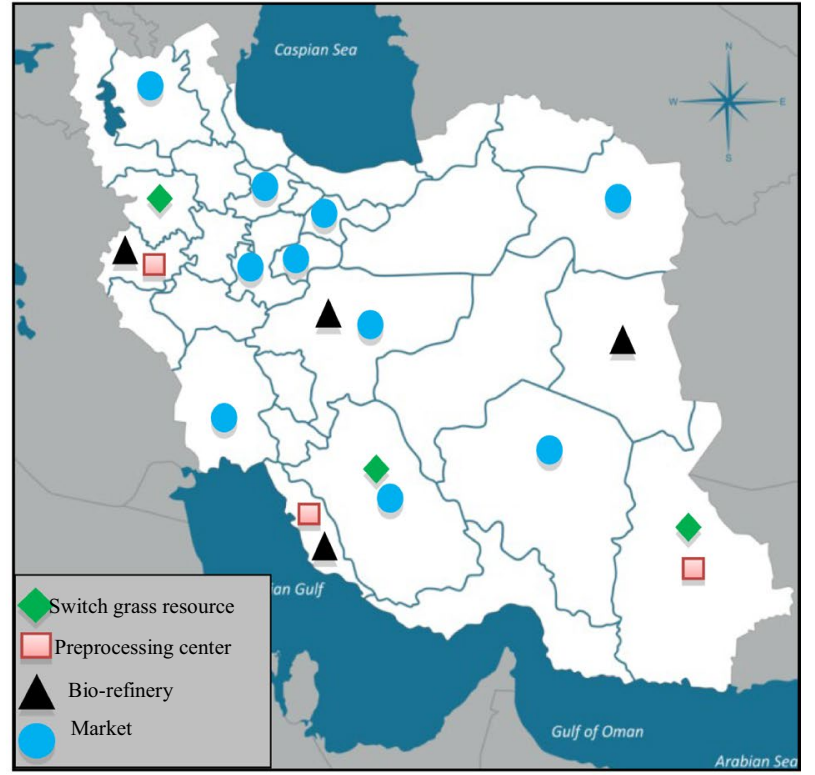

d) Policy 4 .

Fig. 7 Optimal design of the BSC under different carbon policies

way to achieve the sustainable development paradigm in any society, particularly in emerging countries, where fossil fuel output is more reliant. It is also worth noting that the impact of carbon regularity rules on fossil fuel supply chains has been studied. For instance, Labzovskii et al. [63] found that implementing a carbon cap policy reduces carbon emissions by around 1\%,5\% and
$8 \%$ in South Korea, Mongolia, and China, respectively. Since implementing the carbon cap policy in the case study reduces carbon emissions by almost $24 \%$, it can be argued that using the carbon cap policy in the BSC will result in a higher degree of improvement than using fossil fuel supply chains. 
Table 7 Satisfaction degree of objective functions of different models

\begin{tabular}{llll}
\hline Model & $\boldsymbol{Z}$ & $\mu_{1}$ & $\mu_{2}$ \\
\hline Basic & 0.293 & 0.771 & 0.142 \\
Policy 1 & 0.308 & 0.829 & 0.143 \\
Policy 2 & 0.322 & 0.887 & 0.140 \\
Policy 3 & 0.385 & 0.998 & 0.139 \\
Policy 4 & 0.294 & 0.774 & 0.145 \\
\hline
\end{tabular}

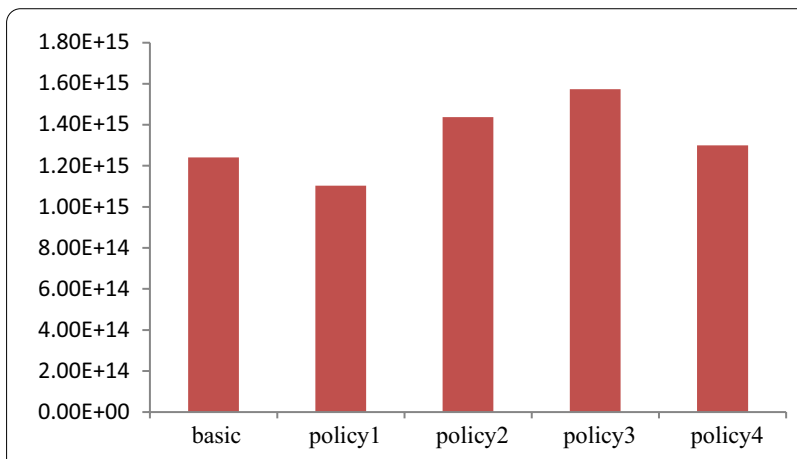

Fig. 8 Economic objective function of different models
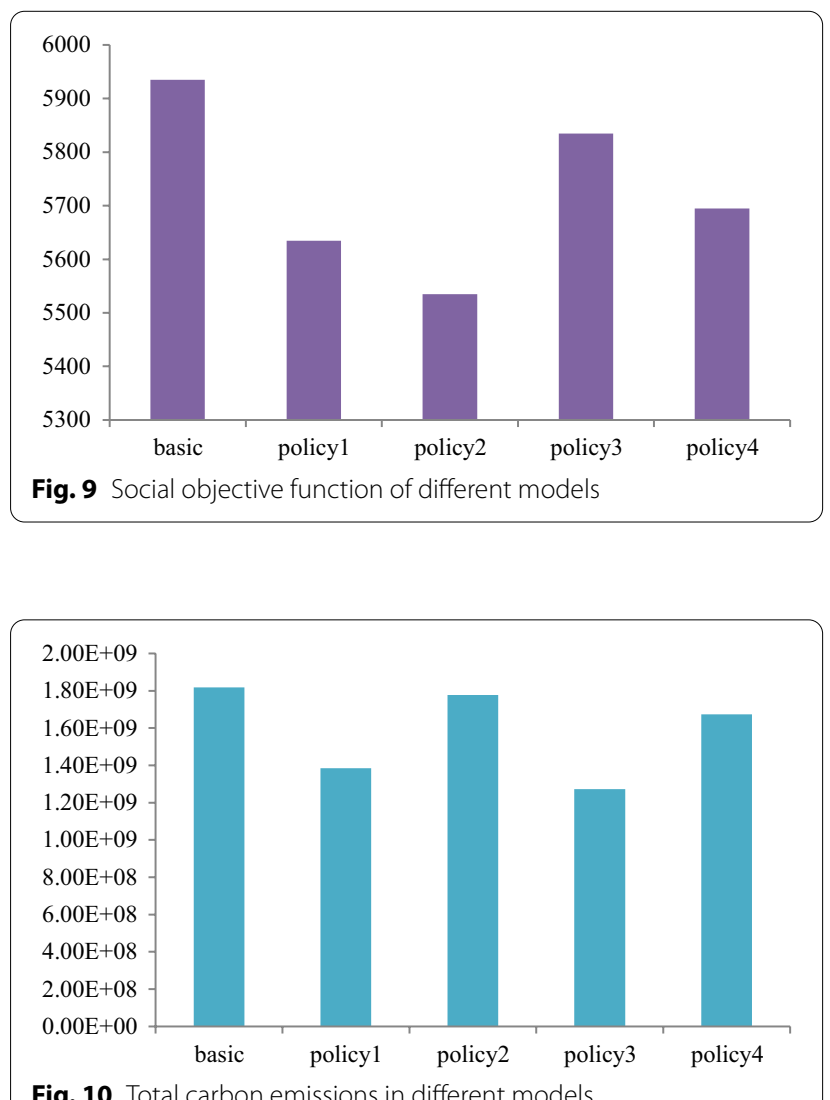

Fig. 10 Total carbon emissions in different models

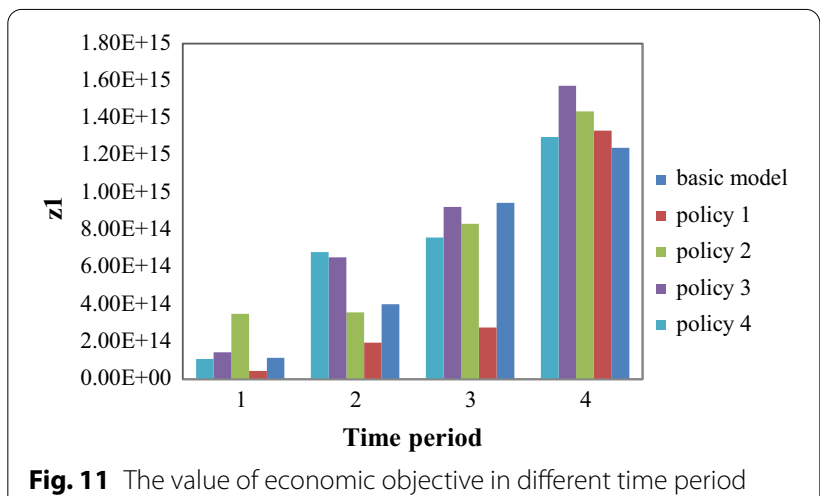

Fig. 11 The value of economic objective in different time period

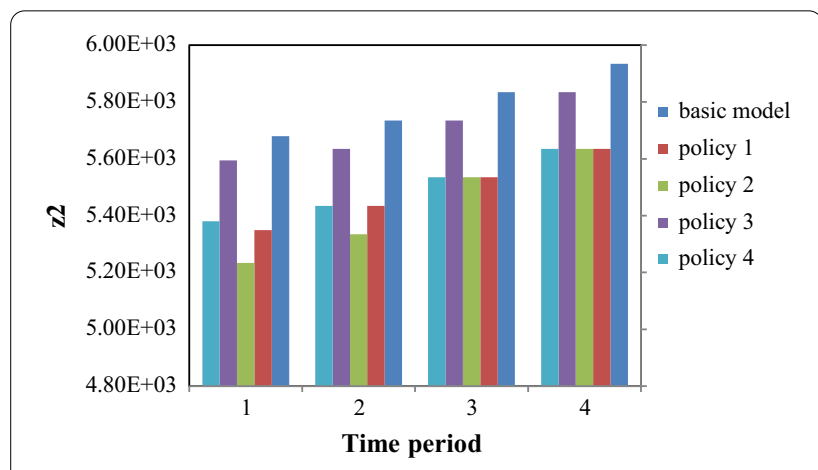

Fig. 12 The value of social objective in different time period

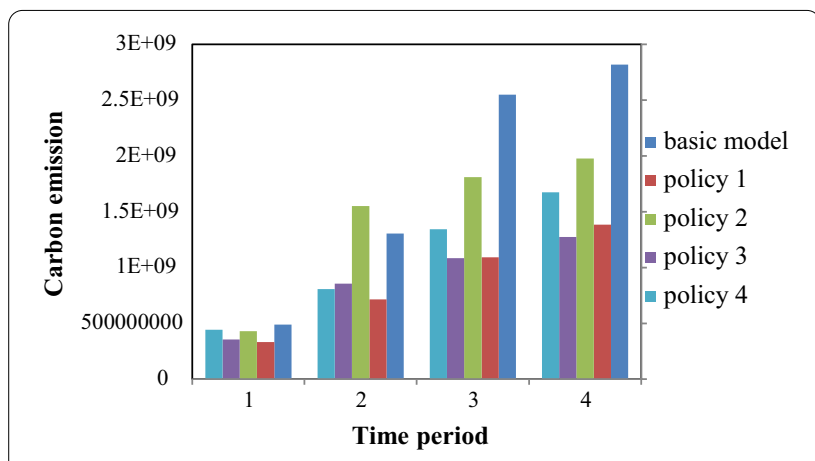

Fig. 13 The amount of carbon emissions in different time period

We explore the impact of time periods on economic and social objectives, as well as carbon emissions, using the basic model and carbon policies. Under the basic model and carbon policies, we investigate the impact of time periods on economic and social objectives, as well as carbon emissions. In the context of carbon policies, Fig. 11 illustrates the worth of economic objective over various time periods. Biofuel production rises as market demand rises, and as a result, the economic objective 


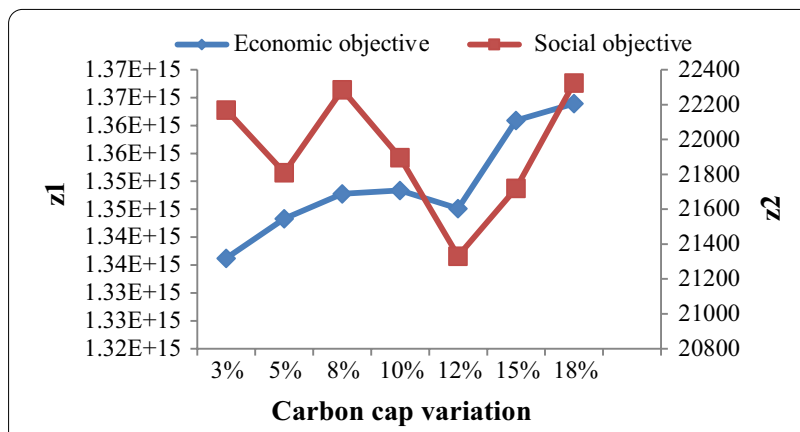

Fig. 14 The effect of the carbon cap on objective functions

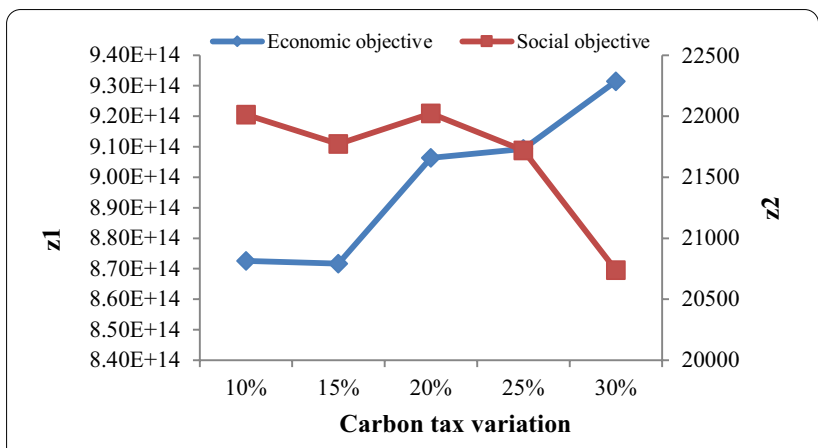

Fig. 15 The effect of the carbon tax on objective functions

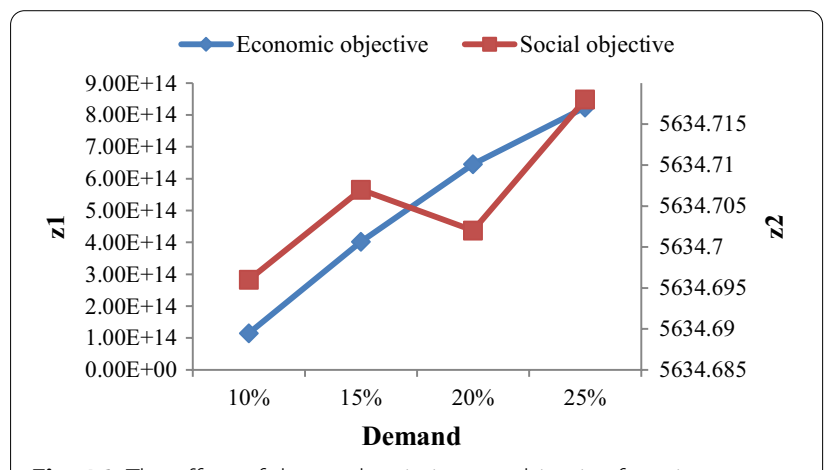

Fig. 16 The effect of demand variation on objective functions

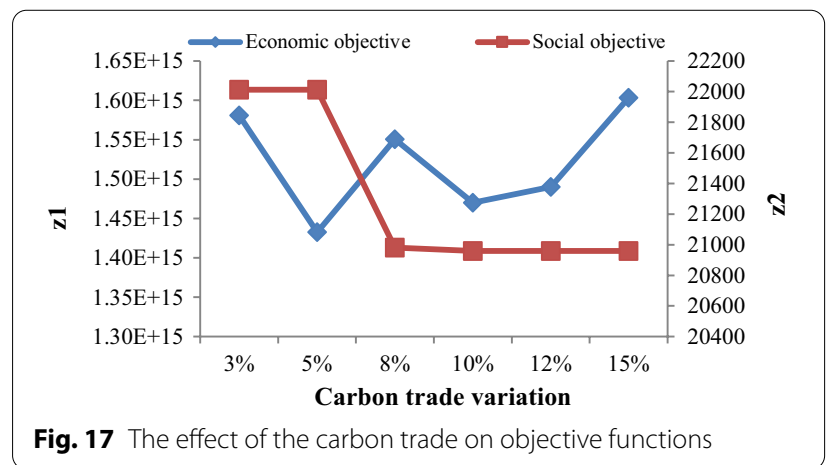

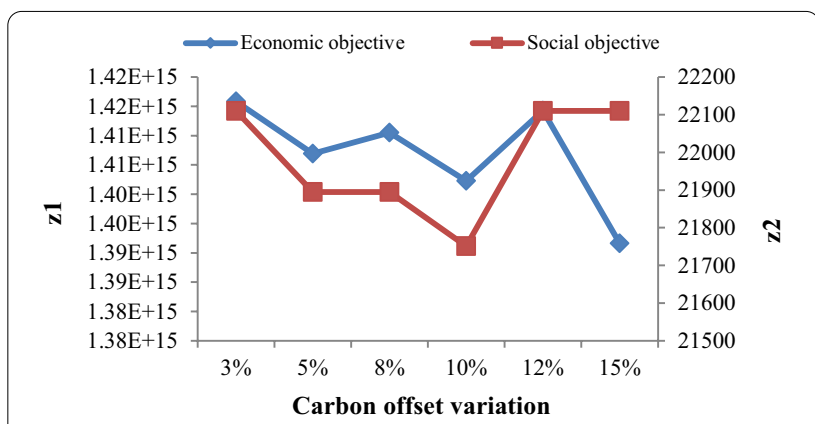

Fig. 18 The effect of the carbon offset on objective functions

value rises as the time period lengthens under the basic model and all carbon policies. The evolution of the social objective over time is shown in Fig. 12. More job opportunities are produced when the number of installed facilities is increased over a longer period of time. As a result, the social objective value rises. The results of time period variation on the amount of carbon emission under various carbon policies are depicted in Fig. 13. Through the passage of time, the volume of carbon emission under basic model and carbon policies grows. Carbon emissions in supply chain sectors such switch grass growth, harvesting, and collecting, switch grass preprocessing and biofuel production grew as biofuel output increased.

\section{Sensitivity analysis}

In this section, a sensitivity analysis is presented to analyze the effects of various factors on economic and social objectives.

The impact of the carbon cap on objective functions is depicted in Fig. 14. The economic value grows as the quantity of carbon cap increases, unless the change is $10 \%$. The social objective, on the other hand, does not follow any particular pattern. Because an increase in carbon allowance can lead to an increase in biofuel production, the economic objective is on the rise. Moreover, increasing biofuel production has no effect on social factors, such as regional development or the number of new job opportunities. As a result, policymakers must establish the ideal amount of carbon allowance for enterprises to accomplish economic growth while also controlling the environmental impacts of production activities.

Figure 15 illustrates how objective functions change as a result of the carbon tax. Unless the carbon tax is higher than $20 \%$, the profit climbs, while the social objective falls as the carbon tax rises. Despite the fact that the carbon tax increases BSC costs, biofuel output rises to meet market demand, canceling out the cost increase. As a result of the increased sales of biofuels, the BSC's profit increases. Moreover, to strike a balance between cost and profit, 
the number of employees is reduced, while the number of laid-off employees rises. It can be deduced that when the carbon tax rises, it will be necessary to boost biofuel production to enhance revenues.

The objective functions alter as demand rises, as shown in Fig. 16. It's worth noting that, according to constraint (8), production must be equal to market demand. As a result, biofuel production in bio-refineries increases as biofuel demand rises, and the economic objective climbs in tandem. Unless market demand rises from 15 to $20 \%$, the social objective is on the rise.

Figure 17 shows that as the amount of carbon trade increases, the BSC profit fluctuates, but once it reaches $10 \%$, it continues to rise. The social objective decreases at first, then stabilizes. When the amount of carbon trade increases, it can be concluded that BSC facilities have more carbon allowance, and as a result, more profit may be made by selling more production.

The economic objective fluctuates as the amount of carbon offset increases, but it begins to decline above a $12 \%$ variation, as shown in Fig. 18. The social objective drops at first, then begins to rise above $10 \%$. It may be stated that as the amount of carbon offset increases, the company's costs rise as more carbon permits are purchased, and profitability falls after a certain point.

\section{Conclusions}

This paper develops a sustainable multi-objective, multi-period, multi-echelon BSC by highlighting the negative effects of fossil fuels and the significance of utilizing renewable energies, such as biofuels. Switch grass resources, preprocessing centers, bio-refineries, and marketplaces are all part of the supply chain. This paper considers all aspects of sustainability, including economic, environmental, and social aspects. In the economic aspect, the BSC profit is maximized by taking into account the revenue as well as the costs of switch grass harvesting, collecting, loading, and storage, transportation, and operation. Job opportunities, regional development, employee job satisfaction, employee's laid-off and lost days due to occupational accidents are all factors included in the social aspect. Different carbon policies, such as the carbon cap, the carbon tax, the carbon trade, and the carbon offset, are evaluated to consider the environmental dimension. Finally, a practical case study is applied to demonstrate the effectiveness of the model. The findings show that: (1) the carbon trade policy increases the profitability of the proposed BSC by about $27 \%$, and this policy yields the largest economic profit.; (2) implementing the carbon cap policy generates the least profit, as it restricts the amount of carbon allowance available for various operational activities; (3) utilizing the carbon tax and carbon offset policies, respectively, increases the economic value by $16 \%$ and $5 \%$; (4) applying a carbon cap, carbon tax, carbon trade, and carbon offset policy reduces the social value by around $5 \%, 7 \%, 2 \%$, and $4 \%$, respectively. As a result, it can be argued that carbon policies are ineffective in increasing the social component of sustainability in the case study under consideration; however, carbon trade policy performs better than other policies, and (5) in the basic model, applying carbon cap, carbon tax, carbon trade, and carbon offset policies reduce carbon emissions by $24 \%, 2 \%, 30 \%$ and $8 \%$, respectively. Overall, the findings show that the carbon trade policy prioritizes the economic, social, and environmental aspects of sustainability. As a result, we can infer that enacting a carbon trade policy achieves the best trade-off between all aspects of sustainability. As a result, policymakers and governments can use this policy to boost economic growth, social indicators, BSC profitability, and reduce carbon emissions.

For future research, considering the uncertainty of real-world characteristics such as market demand may be a good idea. Moreover, selecting various feedstocks such as sugar cane, corn grain, and agricultural residuals could be a useful direction in BSC design. Implementing other solution approaches for addressing the multi-objective model, such as meta-heuristic algorithms, might also be regarded a novel contribution for future research.

\section{Abbreviations}

BSC: Biofuel supply chain; BWM: Best-worst method; FMWM: Fuzzy best-worst method; MILP: Mixed integer linear programming.

\section{Acknowledgements}

The authors are grateful to anonymous referees, editors, and Professor Daniela Thrän for giving the opportunity to review this paper.

\section{Authors' contributions}

The first author proposed the main idea of this study. All authors proposed models, finding up the required data, carried out computations, and analyzed results. All authors read and approved the final manuscript.

\section{Funding}

This research did not get any fund from specific agencies in the public, commercial and not-for-profit sectors.

\section{Availability of data and materials}

The range of parameters and used material are presented in the proposed paper.

\section{Declarations}

Ethics approval and consent to participate Not applicable.

Consent for publication

Not applicable. 


\section{Competing interests}

The authors declare that they have no competing interests.

Received: 21 November 2020 Accepted: 11 October 2021 Published online: 28 October 2021

\section{References}

1. Asadi E, Habibi F, Nickel S, Sahebi H (2018) A bi-objective stochastic location-inventory-routing model for microalgae-based biofuel supply chain. Appl Energy 228:2235-2261

2. EIA (2009) World proved reserves of oil and natural gas, most recent estimates

3. Höök M, Tang X (2013) Depletion of fossil fuels and anthropogenic climate change - a review. Energy Policy 52:797-809

4. Li Y, Kesharwani R, Sun Z, Qin R, Dagli C, Zhang M, Wang D (2020) Economic viability and environmental impact investigation for the biofuel supply chain using co-fermentation technology. Appl Energy 259:114235

5. Kesieme U, Pazouki K, Murphy A, Chrysanthou A (2019) Attributional life cycle assessment of biofuels for shipping: addressing alternative geographical locations and cultivation systems. J Environ Manage 235:96-104

6. Palak G, Ekşioğlu SD, Geunes J (2014) Analyzing the impacts of carbon regulatory mechanisms on supplier and mode selection decisions: an application to a biofuel supply chain. Int J Prod Econ 154:198-216

7. Brennan L, Owende P (2010) Biofuels from microalgae-a review of technologies for production, processing, and extractions of biofuels and co-products. Renew Sustain Energy Rev 14:557-577

8. Hombach LE, Cambero C, Sowlati T, Walther G (2016) Optimal design of supply chains for second generation biofuels incorporating European biofuel regulations. J Clean Prod 133:565-575

9. EIA (2013) US Energy Information Administration. Report Number: DOE/EIA-0484

10. Pérez ATE, Rincón PCN, Camargo M, Marchant MDA (2019) Multiobjective optimization for the design of phase III biorefinery sustainable supply chain. J Clean Prod 223:189-213

11. Apergis N, Payne JE (2014) Renewable energy, output, CO2 emissions, and fossil fuel prices in Central America: evidence from a nonlinear panel smooth transition vector error correction model. Energy Econ 42:226-232

12. Chisti Y (2007) Biodiesel from microalgae. Biotechnol Adv 25:294-306

13. Gray D, White C, Tomlinson G (2007) Increasing security and reducing carbon emissions of the US transportation sector: a transformational role for coal with biomass. National Energy Technology Laboratory

14. Wang M, Han J, Dunn JB, Cai H, Elgowainy A (2012) Well-to-wheels energy use and greenhouse gas emissions of ethanol from corn, sugarcane and cellulosic biomass for US use. Environ Res Lett 7:045905

15. Kesharwani R, Sun Z, Dagli C, Xiong H (2019) Moving second generation biofuel manufacturing forward: investigating economic viability and environmental sustainability considering two strategies for supply chain restructuring. Appl Energy 242:1467-1496

16. Lu J, Sheahan C, Fu P (2011) Metabolic engineering of algae for fourth generation biofuels production. Energy \& Environ Sci. 4:2451-2466

17. Labib SM, Neema MN, Rahaman Z, Patwary SH, Shakil SH (2018) Carbon dioxide emission and bio-capacity indexing for transportation activities: a methodological development in determining the sustainability of vehicular transportation systems. J Environ Manage 223:57-73

18. Sathre R (2014) Comparing the heat of combustion of fossil fuels to the heat accumulated by their lifecycle greenhouse gases. Fuel 115:674-677

19. Benjaafar S, Li Y, Daskin M (2012) Carbon footprint and the management of supply chains: insights from simple models. IEEE Trans Autom Sci Eng 10:99-116

20. Gonela V (2018) Stochastic optimization of hybrid electricity supply chain considering carbon emission schemes. Sustain Prod Consumption $14: 136-151$

21. Li X, Yang D, Hu M (2018) A scenario-based stochastic programming approach for the product configuration problem under uncertainties and carbon emission regulations. Transp Res Part E: Logistics Transp Rev 115:126-146
22. Buyukozkan G, Karabulut $Y$ (2018) Sustainability performance evaluation: literature review and future directions. J Environ Manage 217:253-267

23. Dansereau LP, El-Halwagi M, Mansoornejad B, Stuart P (2014) Framework for margins-based planning: forest bio-refinery case study. Comput Chem Eng 63:34-50

24. Luo Y, Miller S (2013) A game theory analysis of market incentives for US switch grass ethanol. Ecol Econ 93:42-56

25. Marcovecchio I, Thinyane M, Estevez E, Fillottrani P (2017) Capability maturity models towards improved quality of the sustainable development goals indicators data. In 2017 ITU Kaleidoscope: challenges for a Data-Driven Society (ITU K). https://doi.org/10.23919/ITU-WT.2017.82469 89

26. Renzaho AMN, Kamara JK, Toole M (2017) Biofuel production and its impact on food security in low and middle income countries: implications for the post-2015 sustainable development goals. Renew Sustain Energy Rev 78:503-516

27. Zarrinpoor N (2021) Designing a sustainable supply chain network for producing high-value products from waste glass. Waste Manage Res. https://doi.org/10.1177/0734242X21994669

28. FPAC (2011) The new face of the Canadian forest industry. Forest Products Association of Canada

29. Natural Resources Canada (2015) Forest bio economy, bioenergy and bio products. October 27, 2015, http://www.nrcan.gc.ca/forests/industry/

30. Zamboni A, Bezzo F, Shah N (2009) Spatially explicit static model for the strategic design of future bioethanol production systems. 2. Multi-objective environmental optimization. Energy Fuels 23:5134-5143

31. Corsano G, Vecchietti AR, Montagna JM (2011) Optimal design for sustainable bioethanol supply chain considering detailed plant performance model. Comput Chem Eng 35:1384-1398

32. You F, Wang B (2011) Life cycle optimization of biomass-to-liquid supply chains with distributed-centralized processing networks. Ind Eng Chem Res 50:10102-10127

33. You F, Tao L, Graziano DJ, Snyder SW (2012) Optimal design of sustainable cellulosic biofuel supply chains: multiobjective optimization coupled with life cycle assessment and input-output analysis. AIChE J 58:1157-1180

34. Azadeh A, Arani HV, Dashti H (2014) A stochastic programming approach towards optimization of biofuel supply chain. Energy 76:513-525

35. Cambero C, Sowlati T (2016) Incorporating social benefits in multi-objective optimization of forest-based bioenergy and biofuel supply chains. Appl Energy 178:721-735

36. Fattahi M, Govindan K (2018) A multi-stage stochastic program for the sustainable design of biofuel supply chain networks under biomass supply uncertainty and disruption risk: a real-life case study. Transp Res Part E: Logistics Transp Rev 118:534-567

37. Xie F, Huang Y (2018) A multistage stochastic programming model for a multi-period strategic expansion of biofuel supply chain under evolving uncertainties. Transp Res Part E: Logistics Transp Rev 111:130-148

38. Ghosh T, Bakshi BR (2019) Designing biofuel supply chains while mitigating harmful algal blooms with treatment wetlands. Comput Chem Eng 126:113-127

39. Nugroho YK, Zhu L (2019) Platforms planning and process optimization for biofuels supply chain. Renewable Energy 140:563-579

40. Haji Esmaeili SA, Szmerekovsky J, Sobhani A, Dybing A, Peterson TO (2020) Sustainable biomass supply chain network design with biomass switching incentives for first-generation bioethanol producers. Energy Policy 138:111222

41. Bijarchiyan M, Sahebi H, Mirzamohammadi S (2020) A sustainable biomass network design model for bioenergy production by anaerobic digestion technology: using agricultural residues and livestock manure. Energy, Sustain Soc 10:19

42. Rezaei M, Chaharsooghi SK, Kashan AH, Babazadeh R (2020) Optimal design and planning of biodiesel supply chain network: a scenario-based robust optimization approach. Int J Energy Environ Eng 11:111-128

43. Ramudhin A, Chaabane A, Paquet M (2010) Carbon market sensitive sustainable supply chain network design. Int J Manage Sci Eng Manage 5:30-38

44. Marufuzzaman M, Eksioglu SD, Huang Y (2014) Two-stage stochastic programming supply chain model for biodiesel production via wastewater treatment. Comput Oper Res 49:1-17 
45. Ağralı S, Üçtuğ FG, Türkmen BA (2018) An optimization model for carbon capture \& storage/utilization vs. carbon trading: a case study of fossil-fired power plants in Turkey. J Environ Manage 215:305-315

46. Ahmed W, Sarkar B (2018) Impact of carbon emissions in a sustainable supply chain management for a second generation biofuel. J Clean Prod 186:807-820

47. He L, Xu Z, Niu Z (2014) Joint optimal production planning for complex supply chains constrained by carbon emission abatement policies. Discrete Dyn Nat Soc 12

48. GRI (2011) Sustainability Reporting Guidelines. version 3.1

49. McLaughlin SB, Walsh ME (1998) Evaluating environmental consequences of producing herbaceous crops for bioenergy. Biomass Bioenerg 14:317-324

50. Khanjarpanah H, Pishvaee MS, Seyedhosseini SM (2017) A risk averse cross-efficiency data envelopment analysis model for sustainable switch grass cultivation location optimization. Ind Crops Prod 109:514-522

51. ISO (2010) Final Draft International Standard ISO/FDIS 26000 Guidance on Social Responsibility. International Organisation for Standardization, Geneva

52. SAI (2014) Social accountability 8000 . Social Accountability International, New York

53. Torabi SA, Hassini E (2008) An interactive possibilistic programming approach for multiple objective supply chain master planning. Fuzzy Sets Syst 159:193-214

54. Rezaei J (2015) Best-worst multi-criteria decision-making method. Omega 53:49-57

55. Guo S, Zhao H (2017) Fuzzy best-worst multi-criteria decision-making method and its applications. Knowl-Based Syst 121:23-31
56. Afkhami P, Zarrinpoor N (2021) Optimization design of a supply chain for Jatropha-based biofuel from a sustainable development perspective considering international resources and demand: a case study. Ind Eng Chem Res 60:6188-6207

57. Babazadeh R, Ghaderi H, Pishvaee MS (2019) A benders-local branching algorithm for second-generation biodiesel supply chain network design under epistemic uncertainty. Comput Chem Eng 124:364-380

58. Ghaderi H, Babazadeh R, Moini A, Pishvaee MS (2019) Efficiency assessment of switchgrass cultivation areas using sustainable indicators under epistemic uncertainty. Comput Electron Agric 157:12-22

59. Ministry of Roads \& Urban Development (2020). https://www.mrud.ir/en

60. Ghelichi Z, Saidi-mehrabad M, Pishvaee MS (2018) A stochastic programming approach toward optimal design and planning of an integrated green biodiesel supply chain network under uncertainty: a case study. Energy 156:661-687

61. Meyer R, Campanella S, Corsano G, Montagna JM (2019) Optimal design of a forest supply chain in Argentina considering economic and social aspects. J Clean Prod 231:224-239

62. Rahimi M, Ghezavati V, Asadi F (2019) A stochastic risk-averse sustainable supply chain network design problem with quantity discount considering multiple sources of uncertainty. Comput Ind Eng 130:430-449

63. Labzovskii LD, Mak HWL, Kenea ST, Rhee JS, Lashkari A, Li S, Goo TY, Oh YS, Byun YH (2019) What can we learn about effectiveness of carbon reduction policies from inter annual variability of fossil fuel $\mathrm{CO} 2$ emissions in East Asia? Environ Sci Policy 96:132-140

\section{Publisher's Note}

Springer Nature remains neutral with regard to jurisdictional claims in published maps and institutional affiliations.
Ready to submit your research? Choose BMC and benefit from:

- fast, convenient online submission

- thorough peer review by experienced researchers in your field

- rapid publication on acceptance

- support for research data, including large and complex data types

- gold Open Access which fosters wider collaboration and increased citations

- maximum visibility for your research: over $100 \mathrm{M}$ website views per year

At BMC, research is always in progress.

Learn more biomedcentral.com/submissions 